\title{
Schooling and Political Participation in a Neoclassical Framework: Theory and Evidence
}

Filipe R. Campante, Davin Chor

CID Working Paper No. 178

September 2008

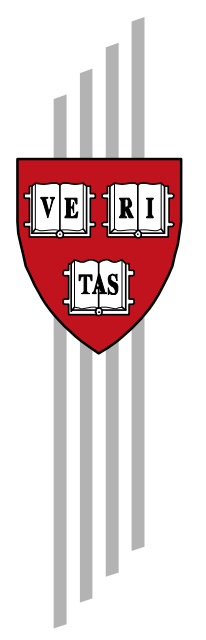

\section{Working Papers Center for International Development at Harvard University}




\title{
Schooling and Political Participation in a Neoclassical Framework: Theory and Evidence*
}

\author{
Filipe R. Campante ${ }^{\dagger} \quad$ Davin Chor ${ }^{\ddagger}$ \\ First draft: January 2008 \\ This draft: September 2008 \\ Comments are Welcome.
}

\begin{abstract}
We investigate how the link between individual schooling and political participation is affected by country characteristics. We introduce a focus on a set of variables - namely factor endowments - which influence the relative productivity of human capital in political versus production activities. Using micro data on individual behavior, we find that political participation is more responsive to schooling in land-abundant countries, and less responsive in human capital-abundant countries, even while controlling for country political institutions and cultural attitudes. We develop these ideas in a model where individuals face an allocation decision over the use of their human capital. A relative abundance of land (used primarily in the least skill-intensive sector) or a scarcity of aggregate human capital will increase both the level of political participation and its responsiveness to schooling, by lowering the opportunity cost of production income foregone. In an extension, we further consider the problem of how much schooling a utility-maximizing ruler would choose to provide. An abundance of land tends to increase political participation ex post, and hence will lead the ruler to discourage human capital accumulation, a prediction for which we find broad support in the cross-country data. Our model thus offers a framework which jointly explains patterns of political participation at the individual level and differences in public investment in education at the country level.
\end{abstract}

Keywords: Education; Human capital; Political participation; Voting; Factor endowments; Culture; State provision of schooling

JEL Classification: D72, D78, I20, I21, O15

\footnotetext{
${ }^{*}$ We gratefully acknowledge the many helpful comments and suggestions from Daron Acemoglu, Alberto Alesina, Pedro Dal Bó, Sue Dynarski, Jeffrey Frieden, Ed Glaeser, Daniel Hojman, Fali Huang, David Laibson, Massimiliano Landi, Erzo F.P. Luttmer, Rohini Pande, Lant Pritchett, Jim Robinson, Dani Rodrik, Andrei Shleifer, Monica Singhal, Kevin Tsui, and participants at the macro lunch (Economics) and faculty research seminar (Kennedy School) at Harvard, the meeting of the International Economic Association (Istanbul 2008), and the annual congress of the European Economic Association (Milan 2008). Chor thanks the Institute for Humane Studies for financial support. Gurmeet Singh Ghumman provided excellent research assistance. All errors are our own.

${ }^{\dagger}$ Harvard Kennedy School, Harvard University. Address: 79 JFK Street, Cambridge, MA 02138, USA. Email: filipe_campante@harvard.edu (Corresponding author)

${ }^{\ddagger}$ School of Economics, Singapore Management University. Address: 90 Stamford Road, Singapore 178903. E-mail: davinchor@smu.edu.sg
} 


\section{Introduction}

The relationship between schooling and human capital on the one hand and political participation on the other has been one of the most widely studied topics in political science and political economy. It is now well established that more educated citizens display a greater propensity to engage in virtually all forms of political activity, including voting, attending political events, staying informed about politics, working on campaigns, contributing money, and signing petitions. ${ }^{1}$ As a result, education has even been labeled "the best individual-level predictor of political participation" (Putnam 1995a, p.68). Building on this, there is also a large body of evidence suggesting that this micro-level relationship extends to the macro level, as education and democracy are positively correlated at the cross-country level. ${ }^{2}$ Since political participation can be viewed as a set of activities aimed at influencing or imposing checks and balances on the government (Verba and Nie 1987), this aggregate relationship would appear to be a natural consequence of that which is so clearly observed at the individual level.

There is nevertheless considerable variation across countries in this link between schooling and political participation (Verba et al. 1987). To give an oft-used example, there is a stark contrast in how politically active citizens of Latin American and East Asian countries are perceived to be: While Latin America is often seen as "a region of unusual political phenomena... with its military coups, riots, demonstrations, and frequent unscheduled changes of governments" (Wynia 1978, p.23), East Asian societies have been broadly characterized as ones where "[h]armony and cooperation were preferred over disagreement and competition [and] the conflict of ideas, groups, and parties was viewed as dangerous and illegitimate" (Huntington 1991, p.24). ${ }^{3}$ This presents an obvious puzzle, since it is the East Asian countries that have generally achieved higher levels of human capital accumulation over the last halfcentury. At first blush, this appears at odds with the strong positive correlation between individual schooling and political participation found within countries. ${ }^{4}$

This paper argues that understanding this cross-country variation requires that we examine how several pertinent country characteristics affect the link between individual schooling and political participation. To this end, use detailed respondent data from the World Values Survey (WVS) and the Comparative Study of Electoral Systems (CSES) on measures of political participation - such as dis-

\footnotetext{
${ }^{1} \mathrm{~A}$ far from exhaustive list of work in this vein includes: Verba and Nie (1987), Rosenstone and Hansen (1993), Putnam (1995b), Bénabou (2000), Dee (2004), Freeman (2004), Milligan et al. (2004), and Glaeser et al. (2007).

${ }^{2}$ The hypothesis that education leads to a more democratic polity is of a fairly old vintage (Dewey 1916, Lipset 1959). That said, the issue of causality and the mechanisms that generate this relationship continue to be actively debated; see Glaeser et al. (2004), Acemoglu et al. (2005), Glaeser et al. (2007), Bobba and Coviello (2007), Castelló-Climent (2008).

${ }^{3}$ These perceptions seem to be broadly supported by the data: In the World Values Survey dataset, Latin American respondents had a mean score of 0.62 on a scale of $0-2$ when asked about their propensity to participate in lawful demonstrations, compared with a mean score of 0.51 in East Asian countries. While Verba et al.'s (1987) seven-nation comparison did not cover Latin America, it is interesting that they found the link between "socioeconomic resources" (such as education) and political participation to be weakest in the one East Asian society (Japan) in their study.

${ }^{4}$ For countries in the World Values Survey, the average total years of schooling in the population aged 15 and above in East Asia was 8.0 in the year 2000, exceeding the average in Latin America (6.7) by more than a year (Barro and Lee 2000). In terms of quality of education, Ratliff (2003) contends that even the best Latin American countries such as Chile do not compare to a country like Malaysia, which is not a top performer by East Asian standards.
} 
cussing politics, attending lawful demonstrations, voting - and regress them against the interaction of respondent's schooling and country-level variables (while controlling for a comprehensive set of other individual characteristics, and country-survey wave fixed effects). This empirical strategy thus enables us to uncover how these country characteristics might systematically influence the micro-level relationship between schooling and political participation. ${ }^{5}$ At present, much of the discussion has centered on such country variables as political institutions and cultural mores to explain the cross-country differences in patterns of citizens' political participation. ${ }^{6}$ Our empirical results do point to a role for institutions (such as compulsory voting laws) and culture (as captured by attitudes towards obedience) in influencing the link between schooling and political participation, but these elements are far from the whole story.

To understand the determinants of political participation fully, we argue that it is important to consider the interplay between the production and political roles of human capital. We focus on a set of economic variables that naturally affects the productivity of human capital in the production sector, namely a country's factor endowment mix. Intuitively, in a country where production is less skewed towards skill-intensive sectors (due to a relative abundance of factors used outside the skill-intensive sectors), a representative individual will have less incentive to use her human capital in production, and thus has a lower opportunity cost of applying her human capital towards political activities instead. We confirm that there is indeed a robust empirical connection involving country factor endowments and the link between schooling and political participation at the individual level. Using the WVS data, Figure 1 illustrates partial scatterplots of a measure of the responsiveness of political participation to schooling with respect to several country variables. ${ }^{7}$ Panel A of the figure depicts a clear upward-sloping relationship, indicating that in countries with a greater per worker land endowment, individual political participation tends to be more responsive to increases in schooling. On the other hand, we find that a higher initial skill endowment tends to dampen the link between participation and schooling (Panel C). (We find no distinct relationship with physical capital in Panel B.)

\section{[FIGURE 1 HERE]}

A key premise in our approach is the idea that political participation requires the use of human capital. From the standpoint of any individual, it has been argued that "political activities have considerable costs [and] require the commitment of time and energy, often in considerable amount" (Verba and Nie 1987,

\footnotetext{
${ }^{5}$ This empirical strategy is similar to that in Solt (2008), who interacts measures of individual income against country income inequality, in order to examine whether country inequality differentially impacts the political engagement of individuals in different income brackets.

${ }^{6}$ For example, Verba et al. (1987) posit that such cross-country variation is linked to "varying patterns of institutional constraint" (p.77).

${ }^{7}$ Specifically, following the empirical work in Section 3, we use the first principal component of five self-reported measures of political participation from the WVS. We first regress this against individual education and a host of other respondent controls, including age, gender, and income decile, for each country-wave separately. (See Table 1 for the full list of individual controls.) We then collected the coefficients on education from the different country-waves and regressed them against country variables, to obtain these partial scatterplots for the education coefficients. (We use the full set of country variables from the Table 1, Column (5) specification.) Details on the data are in Section 3 and the Data Appendix.
} 
p.34), whether this be for voting or attending political events, or even simply gathering news on political developments. Importantly, from the standpoint of the economy as a whole, large amounts of human capital are clearly devoted to political activities, as exemplified by the work of politicians, consultants, lobbyists, and even volunteers. Using Brady et al.'s (1995) terminology, political activity takes up three types of resources: time, civic skills, and money. The first two are directly related to human capital, and money is often used to buy the use of other people's human capital.

We formalize these ideas in a model of citizen behavior in which a representative citizen faces an allocation decision over the use of her human capital, along the lines of Murphy et al. (1991) and Dal Bó and Dal Bó (2004). Citizens trade off the benefit of increased political participation, which is needed to contest the power of the government to tax or expropriate, against the cost of production income foregone. Thus, any socioeconomic or political force that makes the use of human capital in the production sector relatively more enticing will tend to decrease the effort that is channeled towards political participation. Our model, which features multiple production sectors with different skill intensities, highlights two key effects of the factor endowment mix on political participation: a level effect and an elasticity effect. The level effect implies that a greater abundance of the factor used intensively in the least skill-intensive sector (in particular, a greater endowment of arable land for the agricultural sector) will increase each individual's level of political participation, while a greater abundance of the factor used in the most skill-intensive sector will have the opposite effect. ${ }^{8}$ (The effect of factors specific to sectors with an intermediate skill intensity is ambiguous.) The elasticity effect further implies that a higher per-worker land endowment also raises the responsiveness of each citizen's level of political participation to an increase in schooling; once again, the opposite holds in the case of the factor used in the most skillintensive sector. This elasticity effect is precisely what we identify in our empirical work.

We further apply our framework to shed light on the question of why some governing regimes (but not others) have invested so heavily on education, as illustrated by the contrast in average years of schooling attainment in East Asia and Latin America. ${ }^{9}$ To do so, we extend our model to consider a utility-maximizing ruler who decides at an ex ante stage of the game how much education to provide to his citizens, while anticipating how the citizens will thereafter choose to allocate their human capital. The ruler trades off the benefit of increased production against the cost of heightened political participation, which imposes checks on his rent extraction. We show that any variable that raises the ex post equilibrium level of political participation will lead the ruler to decrease human capital provision at the ex ante stage, even if this also decreases final production output. In particular, a greater abundance of the factor input used in the least skill-intensive sector will lead the governing regime to opt for less human capital provision. We provide suggestive evidence in support of this prediction: Countries initially well-endowed

\footnotetext{
${ }^{8}$ It is important to note that this does not mean that more land-abundant countries unconditionally display higher levels of political participation. What the model actually predicts is that an individual in a land-abundant country would be more politically active than a comparable individual with a similar level of schooling in a land-scarce country.

${ }^{9}$ For example, see Lee and Kim (1997) on South Korea, Birdsall et al. (1996) and Brown (2002) on Brazil, and Ratliff (2003) for a more general comparison.
} 
with arable land relative to labor indeed witnessed smaller subsequent increases in average years of schooling. Crucially, this effect is strongest in countries that were not fully democratic, where our model of ruler behavior is likely more applicable, but weakens considerably for democracies.

In sum, our model provides a promising framework for jointly understanding patterns of political participation and state provision of schooling. The role of factor endowments is prima facie consistent with the initial conditions in the motivating East Asia versus Latin America example: In East Asia, with its comparative advantage in production activities that are skill-intensive (due to its relative scarcity in natural resources such as land), individuals are less inclined to channel their energies towards political activities, in contrast to more resource- and land-abundant Latin America. East Asian governments thus rationally chose to raise state provision of education to achieve output growth, as the underlying endowment mix meant that the accompanying increase in political activism would be modest.

A commonly held alternative explanation attributes these differences instead to "values" or "culture". This view, popularly termed the "Confucian values" or "Asian values" debate, suggests that the unique cultural heritage of East Asia places an emphasis on education, as well as on values such as "placing order and harmony over personal freedom, [and] respecting political leadership" (Milner 2000, p.57). We believe our endowment-based explanation is complementary rather than in direct conflict to this view. First, our empirical results on the role of factor endowments are robust to controlling for the interaction between individual schooling and a country measure of attitudes towards obedience. Of note, the interaction term with culture has a significant and quantitatively similar effect in dampening the responsiveness of political participation to schooling: As countries place a greater weight on "obedience", this tends to decrease the size of the coefficient of education in Panel D (Figure 1). This strongly suggests that both forces - factor endowments and culture - are relevant and jointly at play. Separately, our approach also offers a potential explanation for some interesting variation over time, such as the puzzle over why voter turnout has decreased historically in the US and other democracies, even as education levels were increasing (Brody 1978) - what Aldrich (1993) called "the most important substantive problem in the turnout literature". One possible reason could be the onset of skill-biased technological change, which has made human capital relatively more valuable in production activities in the US. Overall, our modeling approach for the determinants of political participation suggests the need to examine more closely why particular values take root in some countries but not in others. While this lies outside the scope of the current paper, it points to a fruitful research agenda in understanding how values themselves can be viewed as an equilibrium outcome of a given set of political and economic conditions.

Our paper follows a growing literature on how initial conditions have influenced long-run country development. This work has identified how initial land and resource abundance (Engerman and Sokoloff 1997, Acemoglu et al. 2002, Naritomi et al. 2007) and the initial disease environment (Acemoglu et al. 2007,2008 ) help to explain the variance in institutional structures observed today, both across and within countries. Similarly, Leamer et al. (1999) argue that initial factor endowments were a root cause of the 
high income inequality observed in present-day Latin America.

Our model also builds on a body of work on the political economy of education provision. Here, Bourguignon and Verdier (2000) have made the point that it can be in the self-interest of the ruling elite to invest in public education when human capital is an engine of economic growth, even if this also increases political participation and erodes their power. ${ }^{10}$ Our specific contribution is to highlight how country characteristics, such as the factor endowment mix, that determine the relative productivity of citizens in political versus production activities can systematically shift this calculus of the governing regime. Along closely related lines, Galor et al. (2008) advance the view that a high concentration of land ownership typically discourages the emergence of human capital promoting institutions such as public schooling initiatives. While their underlying intuition works through the role of landed elites in blocking schooling investments, the mechanism in our model hinges instead on the desire of the ruler in landabundant countries to curtail future increases in citizens' political participation. On a broader note, our paper falls in line with calls for research in the economics of education to recognize that governments view human capital as more than just an input to production and are indeed sensitive to the socio-political implications of expanding education (Pritchett 2003).

In what follows, Section 2 lays out our model of the determinants of individual political participation. Section 3 presents the results based on the WVS and CSES data, confirming the role played by country factor endowments in influencing patterns of political participation. Section 4 extends the model to analyze the ruler's choice over human capital investment, and provides suggestive cross-country evidence consistent with the predictions here. Section 5 concludes. All proofs are in the Appendix.

\section{A Neoclassical Model of Individual Political Participation}

\subsection{The Framework}

We start by developing our main idea on the dual roles of human capital in production and political participation. Consider a representative citizen endowed with a fixed amount of human capital. This individual can choose to allocate her labor effort between different production activities, which generate direct output - tending the land, manufacturing widgets, writing software. She also chooses how much effort to devote to political activities, which do not generate output directly, but can help protect her output from expropriation due to bad governance and rent-dissipation - she can attend political events, work for campaigns, lobby the government, write op-ed pieces, convince her neighbors, and generally keep herself informed of political developments. (Obviously, due to specialization, each citizen in reality need not face these decisions on a daily basis, but the choice is clearly salient at the level of the representative individual.) We thus model an economy of $N$ identical, representative individuals who decide how to

\footnotetext{
${ }^{10}$ See also Acemoglu (2005) who analyzes a ruler's incentives to invest in public goods at the expense of personal consumption in a more general setting. An important strand of this literature has focused on how economic and political elites can attempt to capture or influence the allocation of public spending on education, as well as the evolution of the education system (Galor and Moav 2006, De la Croix and Doepke 2008, Galiani et al. 2008, Zhang 2008).
} 
allocate their labor effort between production activities that will raise their private income, and civic or political activities that will raise their ability to retain a larger share of the income they have earned. This modeling approach is similar to several related papers that have likewise investigated an effort-allocation problem between production and non-production or rent-seeking activities (Murphy et al. 1991, Dal Bó and Dal Bó 2004). We proceed to describe the model's ingredients in order.

\subsubsection{Technology and Endowments}

We consider a neoclassical three-sector economy where $N$ identical individuals are each endowed with three factors of production: $T$ units of land, $K$ units of physical capital, and $H$ units of human capital. Since individuals are identical, we interpret these per worker endowments as country characteristics. Each individual allocates her endowment of human capital across three different production sectors, denoted by subscripts $A$ ("Agriculture"), $M$ ("Manufacturing"), and $S$ ("Services"). We adopt this three-sector, three-factor specification, in view of the empirical findings we uncover on the effects of each of these three factors of production on patterns of political participation.

Each individual's output, $y_{j}$, from each of the sectors, $j \in\{A, M, S\}$, is described by the following Cobb-Douglas production functions:

$$
\begin{array}{r}
y_{A}=h_{A}^{\alpha} T^{1-\alpha} \\
y_{M}=A_{M} h_{M}^{\mu} K^{1-\mu} \\
y_{S}=A_{S} h_{S}^{\sigma} S^{1-\sigma}
\end{array}
$$

where $h_{j}$ is the amount of human capital allocated by her to sector $j$, and $A_{M}$ and $A_{S}$ are Hicks-neutral technology parameters (that for the agricultural sector is normalized to 1). The variable (as opposed to

the subscript) $S$ is defined by $S \equiv \frac{\sum_{i=1}^{N} h_{S i}}{N}$, which is the aggregate amount of human capital allocated to services, expressed in per worker terms. Note that land is specific to Sector $A$, whereas physical capital is specific to Sector $M$, a formulation that allows us to focus solely on the individual's allocation of human capital across different activities as the key decision variable; the sector-specificity can be relaxed without detracting from the underlying intuition. In Sector $S$, each individual benefits from an externality generated by the average level of human capital that all individuals allocate to that sector the more human capital others put in, the more productive each worker will be in that sector. We build in this complementarity to maintain symmetry in the structure of the three sectors, so that a ceteris paribus increase in the country's endowment of a sector-specific factor (in the case of the services sector, this is the average human capital allocated to that sector) will elicit each individual to channel more of her labor effort to that production sector.

We now introduce our key assumption, imposing a natural ranking of agriculture, manufacturing and services in their human capital intensity: 
Assumption $1 \quad 0<\alpha<\mu<\sigma<1$

Sector $S$ uses human capital most intensively, followed by Sector $M$, and then Sector $A$.

\subsubsection{Political Participation}

We adopt a parsimonious formulation of the role of political participation. There is another agent in the model, the "government" or "ruler", who will attempt to extract the citizens' production income for his own private gain. The ruler's ability to tax or expropriate can nevertheless be curtailed if citizens apply some of their labor effort towards political activities to check the executive's power. For example, citizens could engage in public petition drives or open demonstrations. More mundanely, citizens might simply be paying close attention to policy announcements to ensure that the government does not slip unfavorable policies under their noses. In other words, individuals can check the ruler's power if they devote some of their human capital to political participation.

The government succeeds in extracting a fraction $\tau(X)$ of each citizen's production income, where $X=\sum_{i=1}^{N} x^{i}$, and $x^{i}$ is the labor effort devoted by citizen $i$ towards political participation. We require that $\tau \in[0,1], \tau^{\prime}<0$ (the effectiveness of this resistance to expropriation increases with total political participation), $\tau^{\prime \prime}>0$ (such effort is subject to diminishing returns), $\tau(0)=1$ (there is full expropriation if citizens devote no effort to political participation), and also impose the Inada-type assumption that $\tau^{\prime}(0) \longrightarrow-\infty$ (so that it is always optimal to allocate some effort to political participation). ${ }^{11}$ Note that $\tau$ can be viewed either as outright expropriation by a dictator or as more benign forms of taxation by a legitimate government (reflecting the portion of tax revenues that is not returned to citizens say in the form of public goods); our model is flexible in that it admits both interpretations. The $\tau$ function thus specifies how human capital devoted to political participation translates into constraints on the executive's power to tax or expropriate. For example, one can view $\tau$ as encapsulating how features such as the pre-existing institutional landscape or prevailing cultural attitudes might affect the ability of citizens to place effective checks on the government. ${ }^{12}$

\subsubsection{Citizens' Decision Problem}

To summarize, citizens have four alternative uses of their human capital endowment: agriculture $\left(h_{A}\right)$, manufacturing $\left(h_{M}\right)$, services $\left(h_{S}\right)$, and political participation $(x)$. The latter entails an opportunity cost in terms of foregone production income from the former three, but some effort must nevertheless be

\footnotetext{
${ }^{11}$ We assume that the same $\tau$ applies to all three sectors. Differential risks of expropriation - for instance, one could imagine that output is easier to hide in Sector $S$ than in $M$ or $A$-could be easily captured in our framework as this is equivalent to varying the parameters $A_{M}$ and $A_{S}$.

${ }^{12}$ We focus on the role of political participation in exercising checks and balances, but this abstraction is not to deny that there are other sources of private or intrinsic benefits from political activities. For example, individuals who run for office may like the publicity (Diermeier et al. 2005). Instead, this formulation recognizes that there are practical constraints to how much effort an individual can divide between production activities that yield direct income and political activities. One could even make the case that governments should promote some political participation, since decentralized civic groups may be the most efficient means of providing and disbursing some forms of public goods or welfare services.
} 
expended to check the ability of the government to tax production income. ${ }^{13}$

Each individual is risk-neutral and naturally seeks to maximize her income. ${ }^{14}$ The allocation decision facing a representative citizen with human capital $H$ is therefore given by:

$$
\begin{array}{ll}
\max _{x, h_{A}, h_{M}, h_{S}} & (1-\tau(X)) \cdot\left(h_{A}^{\alpha} T^{1-\alpha}+p_{M} A_{M} h_{M}^{\mu} K^{1-\mu}+p_{S} A_{S} h_{S}^{\sigma} S^{1-\sigma}\right) \\
& \text { subject to } \quad h_{A}+h_{M}+h_{S}+x=H \\
& \text { and } \quad h_{A}, h_{M}, h_{S}, x \geq 0
\end{array}
$$

where we have suppressed the superscript $i$ for clarity. Here, $p_{M}$ is the price of manufactured goods and $p_{S}$ is the price of services (both relative to the price of agricultural output). Citizens take these prices as constants, and we solve for a symmetric Nash equilibrium where the actions of all other individuals are taken as given. In particular, we impose the assumption that individuals take as given the aggregate stock of human capital allocated to the services sector, $S .{ }^{15}$

\subsection{Results: Factor Endowments, Schooling and Individual Political Participation}

We start by showing that the model delivers a positive correlation between human capital and political participation at the individual level, consistent with the basic stylized fact overwhelmingly established in the literature. More specifically, solving for the first-order conditions of the above maximization problem and taking comparative statics with respect to $H$ yields:

Proposition 1 For a given individual, an increase in her human capital will lead her to raise labor effort in all activities, namely: $\frac{d h_{A}}{d H}, \frac{d h_{M}}{d H}, \frac{d h_{S}}{d H}>0, \frac{d x}{d H}>0$. In particular, it increases political participation at the individual level.

Proof. All details of proofs are in the Appendix.

Not surprisingly, individuals with more human capital have more units of effective labor, and hence increase their effort allocated towards all activities including political participation. This effect is thus akin to the standard endowment effect in consumer theory; as it turns out, political participation is a "normal good".

\footnotetext{
${ }^{13}$ There are some parallels here with Dal Bó and Dal Bó's (2004) treatment of expropriation activities. Their model considers two production activities that differ in factor intensities, but there is an additional third labor-intensive activity - resource expropriation, broadly construed as crime or other forms of social conflict - that diminishes the share of income that accrues to workers in the legal production sector. In their model, however, increased labor effort in this third activity increases expropriation of the formal sector. In contrast, effort devoted to non-production activities in our model reduces expropriation from the grabbing hand of the ruler.

${ }^{14}$ For simplicity, we disregard any direct utility obtained from human capital, and also a labor-leisure choice. It would be straightforward to add either of these features, without changing the qualitative results.

${ }^{15}$ Our results hold too if we alternatively specify that citizens receive only the share of revenues that accrues to their labor effort, namely a share $\alpha, \mu$, or $\sigma$ of the total production revenues in the respective sectors. Intuitively, this is because the share of revenues that accrues to labor is increasing in the skill-intensity of the sector.
} 
We turn now to our key results concerning how country characteristics - in particular, the per worker endowments of land, physical capital, and human capital - systematically affect the behavior of individual citizens, and hence the extent to which the government's powers will be checked by domestic political participation. We show formally how these country variables influence both the amount of political participation (level effects), as well as the responsiveness of political participation to increases in schooling (elasticity effects).

We start by presenting the level effects, which we consolidate as the following:

Proposition 2 For any given positive level of an individual's human capital, $H$, we have:

1. $\frac{d x}{d T}>0, \frac{d h_{A}}{d T}>0, \frac{d h_{M}}{d T}<0, \frac{d h_{S}}{d T}<0:$ A higher per worker land endowment results in a reallocation of her labor effort away from the manufacturing and services sectors, and towards agriculture and political participation;

2. $\frac{d x}{d K}$ ambiguous, $\frac{d h_{A}}{d K}<0, \frac{d h_{M}}{d K}>0, \frac{d h_{S}}{d K}<0$ : A higher per worker physical capital endowment results in a reallocation of her labor effort away from the agriculture and services sectors, and towards manufacturing, while the effect on political participation cannot be signed explicitly; and

3. $\frac{d x}{d S}<0, \frac{d h_{A}}{d S}<0, \frac{d h_{M}}{d S}<0, \frac{d h_{S}}{d S}>0$ : An increase in the human capital applied to the services sector by other individuals results in a reallocation of her labor effort away from political participation and the agriculture and manufacturing sectors, and towards the services sector.

The mechanisms underlying this proposition are quite intuitive, and bear clear parallels with the logic of the familiar Rybczynski Theorem from international trade. Consider a comparison between two countries, L and E, that are identical except for the fact that L has a greater per worker land endowment. As a result, country L has a greater marginal productivity of labor in agriculture relative to the other two sectors, and this leads individuals in country L to allocate more resources to the landintensive sector, and less to manufacturing and services, when compared to country E. However, the condition $0<\alpha<\mu<\sigma<1$ means that agriculture is less intensive in its labor input requirements than manufacturing or services, so that it is not optimal to transfer effort one-for-one from the latter sectors to the former. Instead, it is individually rational to channel some of the labor effort that is freed up towards political participation, to increase the share of production income that citizens keep. Thus, part 1 of the proposition predicts that the level effect of a greater per worker land endowment is to lead to higher levels of political participation. ${ }^{16}$ The logic behind the level effect of a greater endowment of human capital is very similar, but works in the opposite direction: As more labor is diverted to the most skill-intensive sector, effort allocated to political participation declines (part 3 of the proposition). As

\footnotetext{
${ }^{16}$ Note that it is crucial for our results that there be more than one production sector, with different labor intensities. If agriculture were the only production activity in our setup, then an increase in per worker land endowment would raise labor effort in agriculture at the expense of $x$, and political participation would instead fall.
} 
for the effect of the physical capital endowment, this cannot be signed in general due to the intermediate skill-intensity of the manufacturing sector (part 2).

Two remarks are in order regarding Proposition 2. First, it is important to clarify how this result relates to the stylized observation that urban dwellers tend to be more involved in politics than those in rural areas. The key point is that the proposition does not speak directly to comparisons of individuals within countries. The relevant thought exercise should instead be at the cross-country level. In our previous two-country example, if we take two individuals with comparable characteristics (such as education, gender, income), one from each country, the citizen of country L should display a higher level of political participation than his counterpart in country E, since country L utilizes labor less intensively in production activities. ${ }^{17}$ By the same token, Proposition 2 does not predict that political participation would be unconditionally higher in more land-abundant countries. Instead, what the model implies is that an individual in a land-abundant country would be more politically active than a similar individual with a comparable level of schooling in a more land-scarce country. Second, note that the way the citizen's problem is set up in (4) means that increases in $K$ are completely equivalent in effect to increases in $p_{M}$ or $A_{M}$, and similarly for $S, p_{S}$, and $A_{S}$. Thus, an exogenous rise in the relative goods price or the relative productivity of a given sector will have similar effects on effort allocation as an increase in the endowment of the sector's specific factor, as detailed in the proposition.

The impact of factor endowments goes beyond the level effects described above. More interestingly, Proposition 3 establishes that countries with different factor endowment mixes will also exhibit differences in the magnitude of the elasticity of individual political participation with respect to education. To facilitate derivations, it is helpful to specify a functional form for $\tau(X)$ : We set $\tau(X)=1-A_{x} X^{\sigma_{x}}$, where the constant $\sigma_{x}$ lies in $(0,1)$ to satisfy the desired properties stipulated in Section 2.1, in particular that $\tau^{\prime}<0$ and $\tau^{\prime \prime}>0$. It is helpful to think of $\sigma_{x}$ as capturing the human capital intensity of political participation. (Also, $A_{x}$ is a positive constant satisfying $A_{x}\left(\sum_{i} H^{i}\right)^{\sigma_{x}}<1$, so that $\tau(X) \in[0,1]$ for all $0 \leq X<\sum_{i} H^{i}$.) We can now state our Proposition on the elasticity effects of changes in a country's underlying factor endowments:

Proposition 3 Suppose $\tau(X)=1-A_{x} X^{\sigma_{x}}$. Then:

1. $\frac{d^{2} x}{d H d T}>0$ : A higher per worker land endowment increases the responsiveness of an individual's political participation to her level of education;

2. $\frac{d^{2} x}{d H d K}$ ambiguous: The effect of a higher per worker physical capital endowment on the responsiveness of an individual's political participation to her level of education cannot be signed explicitly; and

\footnotetext{
${ }^{17}$ At first glance, this proposition may also seem at odds with Engerman and Sokoloff (1997), who attribute Latin America's legacy of extractive ruling elites (who faced minimal checks on their power) to the set of resource and geographic endowments that predisposed these economies towards large-scale plantation agriculture manned by slave labor. However, we do not view our theory as directly applicable to this historical period, when there was a general absence of capital-intensive manufacturing industries or skill-intensive service jobs that could have acted as alternative employers of labor.
} 
3. $\frac{d^{2} x}{d H d S}<0$ : An increase in the human capital applied to the services sector by other individuals decreases the responsiveness of an individual's political participation to her level of education.

While we have seen from Proposition 1 that the elasticity of political participation with respect to schooling is positive, Proposition 3 further predicts that the magnitude of this elasticity is larger in more land-abundant countries, and smaller in human capital-abundant ones. Intuitively, when $T$ is large, any increase to a citizen's human capital will lead to a relatively small increase in effort devoted to manufacturing or services: Individuals are less inclined to use the increased human capital in these sectors, given the abundance of land as a complementary input in agriculture. It thus becomes optimal to instead apply more of this additional human capital towards non-production activities, in order to raise the share of income that citizens retain. Put simply, a greater share of a given increase in human capital will be devoted to political activities when land is abundant, because human capital is relatively less valuable in production. Conversely, in countries where $S$ is large, citizens will optimally allocate a relatively large part of any increase in human capital to their effort in the services sector, and political participation thus declines. (Once again, the effect of an increase in $K$ cannot be signed.)

\section{Schooling, Political Participation and Factor Endowments: What the Data Say}

\subsection{Empirical Strategy}

Our theoretical framework highlights how country characteristics, in particular factor endowments, systematically influence citizens' decisions on the extent of their participation in political activities. We now turn to the empirical evidence, which brings together micro-level data on individual political participation on the one hand and macro-level data on country attributes on the other.

To this point, prior studies on the link between schooling and political participation have typically used micro-level survey data for a given country and run specifications of the form:

$$
\text { PolPart }_{i}=\beta_{1} V_{i}+\beta_{2} E d u c_{i}+\varepsilon_{i}
$$

where $i$ indexes individuals. PolPart $i$ is a self-reported measure of political participation, and this is regressed against the respondents' education level $\left(E d u c_{i}\right)$ and a vector of other individual controls $\left(V_{i}\right)$, such as age and gender; $\varepsilon_{i}$ is a standard iid error term. The robust finding here has been a positive and highly significant $\beta_{2}$ coefficient, for a diverse range of political participation measures.

Our theory suggests a novel empirical strategy to demonstrate how key country variables bear on this well-known relationship between individual schooling and political participation. This involves uncovering cross-derivative effects off the interaction of individual education with country characteristics in pooled datasets of country surveys. Concretely, we work with specifications of the form:

$$
\text { PolPart }_{i c t}=\beta_{1} V_{i}+\beta_{2} E d u c_{i}+\beta_{3} E d u c_{i} \times W_{c t}+D_{c t}+\eta_{c}+\varepsilon_{i c t}
$$


where $c$ denotes country and $t$ denotes time. In addition to the individual attributes $\left(V_{i}\right.$ and $\left.E d u c_{i}\right),(7)$ includes interaction terms between individual education and a vector of country characteristics of interest $\left(E d u c_{i} \times W_{c t}\right)$, as well as a full set of country-survey wave fixed effects $\left(D_{c t}\right)$, as explanatory variables for participation $\left(\right.$ PolPart $\left._{i c t}\right)$. The key parameter of interest here is the coefficient vector, $\beta_{3}$, since this captures how country attributes $\left(W_{c t}\right)$ alter the responsiveness of political participation to education at the individual level. Based on the cross-derivatives predicted in Proposition 3, we would expect a positive coefficient when we interact individual education against a measure of country per worker land endowment, and a negative coefficient when we interact individual education against country per worker human capital. Note that we include a time index on the country variables, since the datasets we use feature multiple surveys for the same country conducted in different years. ${ }^{18}$ For this reason, we cluster our standard errors by country, to accommodate correlated but unobservable shocks such as norms of civic expression that might be relatively stable across time. This is reflected in the $\eta_{c}$ error term in (7); the $\varepsilon_{i c t}$ 's are standard iid noise.

One clear advantage of this empirical strategy is that it maximizes the use of the available data, namely all the individual observations across countries and survey waves in the WVS and CSES, as detailed below. Nevertheless, it is important to bear in mind that the estimation of $\beta_{3}$, which reflects how the coefficient of education differs systematically across countries, ultimately still relies on the crosscountry variation in the country characteristics $\left(W_{c t}\right)$ that are interacted with individual education.

\subsection{Data: Measures of Political Participation and Schooling}

Our first source of individual data on political participation is the World Values Survey (WVS), a rich study of socio-cultural attitudes around the world. There are four available waves of the WVS (conducted in 1981-1984, 1989-1993, 1994-1999, and 1999-2004), but our regression analysis draws only on Waves 2-4 because the set of variables is considerably more limited in Wave 1 . This still leaves us with a large number of observations from 47 countries, with representation from all major continents. There are however some data constraints in that the survey waves do not constitute a balanced panel. (Appendix Table 1 summarizes the country coverage in our eventual regression sample.)

Given the multifaceted nature of political participation, we consider a range of measures for our dependent variable, PolPart $i c t$. We draw these measures from the following categorical response questions asked in the WVS (where necessary, we have recoded the responses so that higher values reflect more active participation):

1. Interest in politics (question E023): "How interested would you say you are in politics?" $0=$ Not at all interested, $1=$ Not very interested, $2=$ Somewhat interested, $3=$ Very interested

2. Importance of politics (question A004): "For each of the following aspects, indicate how important

\footnotetext{
${ }^{18}$ We do not index the individual attributes, $V_{i}$ and $E d u c_{i}$ by time, since we do not observe the same individual more than once in the pooled datasets (the surveys are not a longitudinal panel).
} 
it is in your life. Politics."

$0=$ Not at all important, $1=$ Not very important, $2=$ Rather important, $3=$ Very important

3. Discuss politics (question A062): "When you get together with your friends, would you say you discuss political matters frequently, occasionally or never?"

$0=$ Never, $1=$ Occasionally, $2=$ Frequently

4. Petition (question E025): "Now I'd like you to look at this card. I'm going to read out some different forms of political action that people can take, and I'd like you to tell me, for each one, whether you have actually done any of these things, whether you might do it or would never, under any circumstances, do it. Signing a petition."

$0=$ Would never do, $1=$ Might do, $2=$ Have done

5. Demonstrate (question E027): Same question as above, now referring to "Attending lawful demonstrations."

$0=$ Would never do, $1=$ Might do, $2=$ Have done

The first three measures can be viewed as "soft" measures of participation, which relate more to interest in and attitudes towards politics. These stand in contrast to the two "hard" measures (Demonstrate and Petition) of political action. While the "soft" measures capture political activities that are not as publicly visible, we nevertheless view them as informative of the time and effort that individuals routinely put in to stay informed of political developments and government policies, which in turn allows them to exercise a role in checking or demanding accountability from the incumbent. Overall, the use of these diverse variables provides a more comprehensive body of evidence than if we had focused exclusively on any single measure of political participation. ${ }^{19}$

Turning to the explanatory variables, we use each respondent's self-reported highest education level attained (question X025) as a measure of $E d u c_{i}$. This is coded on a categorical scale that ranges from a low of 1 ('Inadequately completed elementary education') to a high of 8 ('University with degree/Higher education - upper-level tertiary certificate'). The WVS also contains a rich set of respondent characteristics - including age, gender, marital status, number of children, employment status, and income decile - which we use in our vector of controls, $V_{i}$, in the regressions.

Our second source of survey data - the Comparative Study of Electoral Systems (CSES) - supplements the empirical analysis with information on voting, a measure of political participation that

\footnotetext{
${ }^{19}$ The WVS contains questions on participation in boycotts (question E026), unofficial strikes (E028), and occupation of buildings or factories (E029). When these variables were included, the results with the first principal component of the participation measures are similar to what we see in Table 1. However, used individually as dependent variables, the results work less well. This is likely because these latter three measures are more extreme forms of political participation that elicit more 'no participation' responses, hence resulting in less observed variance. Moreover, these arguably speak less directly to political action; for example, the question on strikes and occupying buildings could relate more to labor relations.
} 
has traditionally been used in this literature. ${ }^{20}$ The CSES is a collaborative cross-country project that undertakes election surveys in the aftermath of national elections, typically within one year. As with the WVS, local researchers take the lead in collecting the survey data, employing statistical sampling methods to ensure a respondent pool that is representative of the electorate. Two modules of data are available (Module 1 for elections from 1996-2002, Module 2 for 2001-2006), with the key difference being that Module 2 contains an expanded set of questions. Pooling the data from the two CSES modules gives us survey data from 42 legislative or presidential elections in 25 countries. This includes: (i) a binary variable for whether the respondent voted in the election in question; (ii) respondent education, which is also reported on a 1-8 categorical scale comparable to the WVS; and (iii) a set of other individual controls similar to the WVS. We will use this voting variable as an alternative PolPartict measure in logit regressions based on (7) to provide corroborating evidence for our theory. It should be noted though that the country coverage here is more limited, given the shorter history of the CSES project: The sample consists mostly of European and North American countries, with no post-election surveys from Africa included yet.

This individual survey data from the WVS and CSES is merged with several country-level variables $\left(W_{c t}\right)$, in particular each country's per worker arable land, physical capital, and human capital stocks. The country controls used also include real GDP per capita, population, gini coefficients, and democracy. These variables are all derived from standard sources in the macro literature, and the details on their construction can be found in the Data Appendix. In the baseline specifications, we use 5-year lagged averages of these country variables for each survey wave/module (the results are similar with contemporaneous measures; results available on request). For descriptive statistics for all of our variables, see Appendix Tables 2 and 3 for the WVS and CSES respectively.

\subsection{The Evidence}

We now present the empirical findings on the determinants of individual political participation and the role played here by country characteristics. We start by employing a principal components analysis, to summarize the information contained in the five WVS measures of political participation. Table 1 reports the results from OLS regressions for the WVS dataset, using the first principal component of the five participation measures as the dependent variable, PolPart $t_{i c t}$. (Tables 2-3 will later report results for each of the separate participation measures.)

\section{[TABLE 1 HERE]}

Column (1) presents the baseline regression which includes only individual-level variables; this is equivalent to (7) with $W_{c t}$ as a null vector. This serves as a point of comparison with the existing

\footnotetext{
${ }^{20}$ The WVS does not ask a direct question on respondents' voting history. It does include a question asking respondents which party they would vote for if an election were held tomorrow, to which one of the potential responses is: 'I would not vote'. This is unfortunately an indirect question on voting intentions, and does not capture whether respondents would in fact bear the costs of going to the polls to translate their intentions into action.
} 
empirical literature, corroborating the standard result that political participation is indeed increasing in schooling for our pooled country sample. Of note, this effect is significant despite our controlling for the income decile of the respondent, so education itself does have explanatory power for patterns of political participation that is independent of income status. The effects of the other individual controls are relatively unsurprising: Older citizens are more politically active, but this effect tapers off beyond a certain age. Women are less politically active. There is no significant effect of marital status, but the propensity towards participation does decrease for respondents with more children, possibly because such respondents have less time available. Students are more politically active, as are employed individuals. Higher income earners tend to be more politically active. These results remain very robust across all specifications, even as we subsequently introduce country characteristics as explanatory variables. ${ }^{21}$

Following the empirical strategy outlined above, we introduce the three country factor endowment measures in Column (2) by interacting them with individual education. (The level effects of these country characteristics are absorbed by the country-wave fixed effects, $D_{c t}$.) We find evidence in favor of a positive and significant effect on the interaction terms with $\log (T / L)$ and $\log (K / L)$, as well as a negative effect on the interaction with $\log (H / L)$. This matches the prediction from Proposition 3 of our model that political participation will be more responsive to increases in individual schooling in countries with a higher land endowment. This is consistent with the intuition that the opportunity cost of production income foregone from devoting more effort to political activities is lower in such countries, where the industry structure places more emphasis on land- rather than skill-intensive sectors. Likewise, we match the prediction of a negative cross-derivative with respect to the country's average human capital endowment, so that political participation is less responsive to education in countries with a high $\log (H / L)$. Intuitively, the opportunity cost of production income foregone is much higher in skill-intensive economies, thus dampening the responsiveness of individual's political participation to increases in schooling.

These patterns show up consistently, even as we subject the data to more checks. In Column (3), we exclude potential outliers, removing those countries that are more than three standard deviations away from the sample mean for any one of the three factor endowments. This drops Singapore (with a very low $\log (T / L))$ and Uganda (with a very low $\log (K / L)$ ), but the results remain largely unaffected. Column (4) adds two new interaction terms, of education with country real GDP per capita and with country working age population. While this reduces the significance of the $E d u c_{i} \times \log (K / L)$ term, for which our theory has no unambiguous prediction, it nevertheless gives strong confirmation that the arable land and human capital interactions are not just picking up country wealth or size effects.

Column (5) adds interaction terms involving several more country attributes that a priori might matter for explaining patterns of political participation. These include income inequality (gini coefficient), ethnic fractionalization (ELF), a democracy index, and a socialist dummy (for communist and former

\footnotetext{
${ }^{21}$ We have experimented with several additional respondent controls, namely: a full set of occupation dummies, and the size of town of residence. These did not detract from our core results (available on request), but we excluded these controls from our tables as these were available for a much smaller number of countries and reduced our sample size substantially.
} 
communist countries). The first two of these variables speak to the issue of potential cleavages within the polity, which could in principle affect the degree of political activism among citizens. The democracy variable allows us to control for citizens' formal access to political voice. On the other hand, the socialist dummy is a means (albeit a fairly crude one) to try to capture the extent to which the institutions of schooling are used by the state for the purposes of indoctrination or socialization.

We also consider a control for cultural values, which have played a prominent role in this literature in explaining differences in political activism across countries. This is based on the following WVS question (where the responses have been recoded to be increasing in obedience):

- Obedience in the workplace (question C061): "People have different ideas about following instructions at work. Some say that one should follow one's superior's instructions even when one does not fully agree with them. Others say that one should follow one's superior's instructions only when one is convinced that they are right. With which of these two opinions do you agree?" $0=$ Must be convinced first, $1=$ Depends, $2=$ Follow instructions

We take the mean response by country-survey wave to this question as an indicator of how willing citizens are to accept and defer to external sources of authority, and hence as a proxy for the cultural preferences of citizens for political consensus rather than open disagreement. (In the context of our model from Section 2, a higher cultural preference for obedience can be viewed as a case where the parameter $\sigma_{x}$ in the $\tau(X)=1-A_{x} X^{\sigma_{x}}$ function is small, namely where cultural attitudes against civic disobedience make it difficult for the citizenry to translate political participation into effective constraints on the government.)

Reassuringly, our results in Column (5) remain broadly unchanged for the education interactions with country factor endowments, with most of the auxiliary interactions exhibiting insignificant coefficients. Of note, however, the regression does suggest that the culture hypothesis is important as a complementary explanation for patterns of political participation: The interaction term between individual education and "obedience" indicates that in countries that value such attitudes and behavior, political participation tends to be less responsive to increases in individual schooling.

As a further robustness check, Column (6) includes the full set of interactions between respondent income decile and the country-wave fixed effects (namely, Income $e_{i} \times D_{c t}$ ), to check that the $E d u c_{i} \times W_{c t}$ terms are indeed picking up the effects of education rather than that of income (which tends to be highly correlated with education). The use of this extensive set of controls reduces the significance of the $E d u c_{i} \times \log (H / L)$ coefficient, although the sign of the point estimate remains negative. Last but not least, Column (7) imputes the value of missing individual variables by assigning it the mean value observed within the relevant country-survey wave in the WVS, while also introducing a set of dummy variables to indicate whether the individual control in question was imputed; this follows Glaeser et al. (2005), who adopt this procedure as they argue that the missing observations in the WVS are not entirely 
random. We find this leaves our main conclusions intact, with the interaction between education and $\log (H / L)$ now negative and significant again at the $10 \%$ level.

The effects that we identify are quantitatively non-trivial. Focusing as an example on the Column (5) specification, evaluating all other country characteristics at the sample median, an increase in land endowment $(\log (T / L))$ from the 10th to the 90th percentile country level would raise the responsiveness of political participation to education from an initial value of 0.244 to 0.327 , a $34 \%$ increase. Repeating this calculation for $E d u c_{i} \times \log (H / L)$, a similar move up the country pecking order of human capital endowment would decrease the responsiveness of participation to education by about $22 \%$. Interestingly, the quantitative implications of the coefficient of $E d u c_{i} \times$ Obedience fall within the same order of magnitude, indicating once again the complementary nature of the culture hypothesis: The derivative of participation with respect to schooling is about $21 \%$ lower in a country with the 90 th level of "Obedience" compared to the 10 th percentile.

These conclusions based on the first principal component carry over in large measure when we examine each of the WVS political participation variables separately. Table 2 reports the results from OLS specifications, while Table 3 undertakes ordered logit regressions instead (since the dependent variables are categorical in nature). For the sake of brevity, we report only two regressions for each measure of political participation: (i) a lean specification containing the interactions with only the three country factor endowment variables, following Column (2) in Table 1; and (ii) a full specification with the most extensive set of controls, following Column (7) in Table 1. (A comprehensive set of specifications is available on request, but the results are similar.) Regardless of whether OLS or ordered logit is used as the estimation procedure, the findings reinforce the main message of a positive cross-derivative between education and country land endowment, and a negative cross-derivative between education and country human capital. We typically also find a negative coefficient on the "obedience" interaction. These results are particularly strong for the Interest in Politics, Importance of Politics, and to a slightly lesser extent, the Demonstrate measures. Note in particular that the point estimates are always in accord with their predicted sign from the theory (with a single exception for the very last ordered logit regressions using Petition, where the $E d u c_{i} \times \log (H / L)$ coefficient is positive but not significant).

\section{[TABLES 2 AND 3 HERE]}

We turn next to the voting data from the CSES. Given the binary nature of the voting variable, we estimate (7) via a logit regression, with the findings reported in Table 4 . While voting is an important form of political participation that is widely studied, it is also a very distinct and peculiar one. First of all, Verba and Nie (1987) have described it as "the only political act requiring relatively little initiative" (p.77). This might lead us to expect that the logic highlighted by our framework would be less prominent with voting, although we would still expect it to have some influence in light of the fact that different types of political activities are correlated at the individual level. In addition, voting is subject to institutional 
idiosyncrasies that hardly affect other activities; for instance, a good number of countries have compulsory voting laws that make it a de jure mandatory duty of citizens. While the extent to which such laws are enforced varies across countries, it is important to control for the presence of compulsory voting in the vector $W_{c t}$ of country characteristics, since they do influence citizens' incentive to vote, and by extension the link between voting and education as well. ${ }^{22}$

\section{[TABLE 4 HERE]}

In Table 4, Column (1) confirms the basic positive correlation between education and the propensity to vote in the pooled CSES data, but introducing the three factor endowment interactions with education in Column (2) yields a set of statistically insignificant results. That said, once we further control for the interaction between individual education and a dummy variable for compulsory voting (variable obtained from the CSES), we obtain a positive and significant coefficient (at the $10 \%$ level) for the $E d u c_{i} \times \log (T / L)$ term, so that countries with a higher land endowment feature a stronger positive relationship between schooling and participation in voting (Column (3)). This pattern persists in Column (4) where we also interact education with country real GDP per capita and with population size, and in Column (5) where we introduce the full set of education interactions that we have considered. ${ }^{23}$ In these two columns, we also find a positive and significant effect of country physical capital on the relationship between voting and education. We get similar results even when we include the interactions between individual income and country-module fixed effects (Column (6)), or impute values for the missing individual variables (Column (7)). There are nevertheless indications that voting is somewhat different from the other measures of political participation, in that it is not governed by the exact same patterns that our model would predict: We do not find a negative cross-derivative effect between schooling and country human capital, nor do we find a significant effect of the interaction term with the measure of attitudes toward obedience. Instead, we find that democratic institutions tend to reinforce the positive education-voting correlation, while greater ethnic fractionalization tends to dampen this relationship. Overall though, we find the evidence broadly supportive of the role of factor endowments, particularly a country's land endowment.

In sum, we find strong evidence that confirms the importance of country characteristics, notably the set of factor endowments, in influencing political participation, and in particular its responsiveness to individual levels of education. These effects are consistent with the theory proposed in Section 2.

\section{Factor Endowments and the Public Provision of Schooling}

We now turn to a natural extension of our framework for modeling the determinants of political participation, to address one of the key motivating questions discussed in the introduction, namely what might

\footnotetext{
${ }^{22}$ Verba et al. (1987) cite a study by Galen Irwin, who compared two elections in the Netherlands. In a 1970 election in which voting was optional, the education-turnout relationship was "moderately strong", whereas for a 1967 election conducted under compulsory voting, the turnout was "almost equal across educational levels" (p.8).

${ }^{23}$ There are no country outliers in terms of factor endowments along the lines of the criterion used in Table 1, Column (3), given the smaller sample in the CSES.
} 
lead different country governments to select different paths of human capital accumulation. While the model in Section 2 took the level of human capital as given, we now extend it to examine how that level of human capital is determined in the case of a ruler who decides at an ex ante stage how much education to provide to his citizens. This is an extreme case, a fully nondemocratic setting that puts aside many nuances in political systems, but we nevertheless view it as an important benchmark that sheds light on the role that initial conditions can play in influencing the incentives of governing regimes to encourage human capital accumulation. Moreover, governments typically do in practice exercise a lot of say over the quantity and quality of schooling, be it by direct provision or regulation of private schooling.

It is natural to model this decision by considering the motivations of the ruler who was implicitly in the background of the effort-allocation problem of individual citizens. We consider the ruler's objective to be maximizing the utility he derives from the income he expropriates, and we assume this self-interested and rational ruler is able to foresee exactly how individuals will behave when provided with a certain amount of human capital through schooling.

\subsection{Solving for Aggregate Political Participation in Equilibrium}

In order to solve the ruler's problem, we need first to solve for what happens in the aggregate in our economy when the decisions of all $N$ individuals are put together. This is a necessary step, since it is aggregate political participation, $X \equiv N x$, which determines the share of income which the ruler appropriates. The comparative statics for political participation at the individual level, $x$, which we have analyzed so far take as given the decisions of all other individuals, particularly with regards to the human capital externality that is present in the services sector. To solve for the equilibrium, we impose the symmetry assumption $h_{S i}=h_{S}$ for all $i$, which in turn implies that $S=h_{S}$. Some straightforward algebra then yields closed-form solutions for our main endogenous variables, which we consolidate in:

Proposition 4 Suppose $\tau(X)=1-A_{x} X^{\sigma_{x}}$. Then:

$$
\begin{aligned}
h_{A} & =\left(\frac{\alpha}{\sigma A_{S} p_{S}}\right)^{\frac{1}{1-\alpha}} T \\
h_{M} & =\left(\frac{\mu A_{M} p_{M}}{\sigma A_{S} p_{S}}\right)^{\frac{1}{1-\mu}} K \\
h_{S} & =\frac{N \sigma}{\sigma_{x}+N \sigma} H-\frac{\sigma}{\alpha} \frac{N \alpha+\sigma_{x}}{N \sigma+\sigma_{x}} h_{A}-\frac{\sigma}{\mu} \frac{N \mu+\sigma_{x}}{N \sigma+\sigma_{x}} h_{M} \\
x & =\frac{\sigma_{x}}{\sigma_{x}+N \sigma} H+\frac{(\sigma-\alpha) \sigma_{x}}{\alpha\left(N \sigma+\sigma_{x}\right)} h_{A}+\frac{(\sigma-\mu) \sigma_{x}}{\mu\left(N \sigma+\sigma_{x}\right)} h_{M} \\
X & =\frac{N \sigma_{x}}{\sigma_{x}+N \sigma}\left[H+\frac{\sigma-\alpha}{\alpha} h_{A}+\frac{\sigma-\mu}{\mu} h_{M}\right]
\end{aligned}
$$

It is interesting to consider what happens when $N \rightarrow \infty$, namely when the number of individuals becomes arbitrarily large. It is clear from (11) that the political participation of each individual tends 
to zero, as there is a free-rider problem affecting citizen's incentives to contribute effort to keep the ruler's expropriation in check; this is however not so with aggregate political participation, as can be seen from (12). Of note, (8), (9) and (12) jointly imply that a larger endowment of any of the three factors of production $(T, K$, and $H$ ) unambiguously raises aggregate political participation, which stands in contrast to the comparative statics for individual participation derived in Proposition 2. The reason behind this disconnect between the individual-level versus aggregate predictions is clearly the human capital externality in the services sector. Consider for instance the effect of an increase in $K$. Proposition 2 shows that it has an ambiguous effect on an individual's political participation, but also that it decreases $h_{S}$, the amount of human capital she devotes to the services sector. When all citizens are taken together, this means a decrease in $S$, which in equilibrium induces all individuals to reduce their labor effort in the services sector and divert more towards political participation; this is what leads to an unambiguously positive effect of $K$ on aggregate participation, $X$.

Furthermore, from (12), out of every extra unit of human capital $H$ that is provided, a fraction equal to $\frac{\sigma_{x}}{\sigma}$ (when $N \rightarrow \infty$ ) will be devoted in the aggregate to political activities. ${ }^{24}$ This means that the more skill-intensive these political activities are relative to production, the more human capital the citizenry will devote to political participation in equilibrium. This is consistent with the observation that investment in education has not always translated into greater output and faster growth, and in fact revisits the idea that this might actually be due to the relative attractiveness of production versus non-production or rent-seeking activities (North 1990, Murphy et al. 1991, Pritchett 2001).

\subsection{Choosing the Level of Human Capital: The Ruler's Problem}

We can now return to the ruler's decision on human capital provision. Let us consider the problem in its simplest dynamic setting, that of a two-period model, in which the ruler maximizes the utility he derives from consumption. (This could easily be extended into an infinite-horizon problem.) The timeline of events is illustrated in Figure 2. In period 1, the ruler decides on the level of human and physical capital to invest in ( $H$ and $K$ are choice variables), while taking the land endowment as given. This is meant to capture the distinction that both forms of capital are the outcome of investment decisions, whereas the amount of land is largely constrained by natural endowments. ${ }^{25}$ Period 2 then sees individual citizens allocating their human capital $H$ between the various production sectors and political participation. Note that the ruler makes his decisions over $H$ and $K$ in period 1, fully cognizant of how the labor effort decision in period 2 will play out, so the game can be solved by backward induction.

\section{[FIGURE 2 HERE]}

\footnotetext{
${ }^{24}$ Note that a necessary condition for an interior solution is $\frac{N \sigma_{x}}{\sigma_{x}+N \sigma}<1$, which is the same as $\sigma_{x}<\frac{N}{N-1} \sigma$. When $N \rightarrow \infty$, this boils down to $\sigma_{x}<\sigma$. Intuitively, if political participation is more intensive in human capital than any type of production activity, the strong incentives to devote human capital to politics would lead us into a corner solution.

${ }^{25}$ This is clearly a simplified framework, ignoring the role of private agents decisions in capital accumulation, but it nevertheless has the advantage of highlighting the main tradeoff between the production and political roles of human capital, from the ruler's standpoint.
} 
Since we have already solved in Section 2 for the period 2 allocation of labor effort chosen by citizens, we focus here on the period 1 decisions made by the ruler. Suppose in period 1 that the ruler has an initial amount of resources, denoted by $Z$, measured in terms of the numeraire good. He can choose to consume immediately an amount $C_{1}$ of these resources, but whatever is left can be transformed into human capital, $H$, and/or physical capital, $K$, according to the production functions, $F_{H}(\cdot)$ and $F_{K}(\cdot)$. (We assume these production functions are twice differentiable, increasing, and strictly concave, namely for $j \in\{H, K\}, F_{j}^{\prime}(\cdot)>0, F_{j}^{\prime \prime}(\cdot)<0$.) Both types of capital will be used in production by individual citizens in period 2, thereby increasing the production output of the economy; the ruler captures a share $\tau(X)$ of that output for his own consumption, $C_{2}$. The ruler's problem can thus be written as: ${ }^{26}$

$$
\begin{aligned}
\max _{H, K} & C_{1}+C_{2} \\
& \text { subject to } \quad C_{1}+F_{H}^{-1}(H)+F_{K}^{-1}(K)=Z \\
& \text { and } \quad C_{2}=\tau(X) \cdot N\left(h_{A}^{\alpha} T^{1-\alpha}+p_{M} A_{M} h_{M}^{\mu} K^{1-\mu}+p_{S} A_{S} h_{S}\right) \\
& \text { and } \quad(8),(9),(10),(12) \\
& \text { and } \quad K, H \geq 0 .
\end{aligned}
$$

Assuming an interior solution, the optimal amount of $H$ and $K$ from the ruler's standpoint must satisfy the first-order conditions:

$$
\begin{aligned}
\tilde{N} p_{S} A_{S}\left[\tau^{\prime}(X) X+\tau(X)\right] & =\frac{1}{F_{H}^{\prime}(H)} \\
\tilde{N} p_{S} A_{S} \frac{\sigma-\mu}{\mu}\left(\frac{\mu A_{M} p_{M}}{\sigma A_{S} p_{S}}\right)^{\frac{1}{1-\mu}}\left[\tau^{\prime}(X) X+\tau(X)\right] & =\frac{1}{F_{K}^{\prime}(K)} .
\end{aligned}
$$

where $\tilde{N}=\frac{N^{2} \sigma}{N \sigma+\sigma_{x}}$ is a positive constant that depends only on model parameters. The first term in square brackets in (16) and (17), $\tau^{\prime}(X) X$, captures the marginal "political" cost of providing citizens with an extra unit of human capital: It will increase political participation, and thus reduce the share that can be captured by the ruler. On the other hand, the second term, $\tau(X)$, represents the marginal benefit, which stems from the additional output that is generated, part of which goes to the ruler. The marginal benefit, net of the marginal political cost, has to equal the marginal cost of factor provision, which is foregone consumption. We can see that the ruler faces a type of "Laffer curve" over his ability to extract output: If he were to set the expropriation rate at its highest (by minimizing political participation through very low levels of human and physical capital), production would be very low as a result.

We now characterize how the ex ante choice of $H$ will be affected by the key variables of the model. Define $G(X) \equiv \tau^{\prime}(X) X+\tau(X)$. It is easy to show, using the implicit function theorem applied to (16) and the second-order conditions of the optimization problem, that for any variable or parameter of

\footnotetext{
${ }^{26}$ We specify the ruler's utility to be linear in his consumption, and assume away any intertemporal discount factor. It is easy to see that any concave utility function and conventional discount rate would only add to notation, without any further insight for our purposes.
} 
interest $j$, we will have the sign of $\frac{\partial H}{\partial j}$ being equal to the sign of $\frac{\partial G}{\partial j}$. Moreover, we have:

$$
\frac{\partial G}{\partial j}=\left[\tau^{\prime \prime}(X) X+2 \tau^{\prime}(X)\right] \frac{\partial X}{\partial j}=\left(1+\sigma_{x}\right) \tau^{\prime}(X) \frac{\partial X}{\partial j} .
$$

A crucial conclusion immediately follows, given that $\tau^{\prime}(X)<0$ : Any variable that increases aggregate political participation will lead to less investment in human capital by the ruler. So long as a variable will increase political participation in period 2, this will be sufficient to lead the ruler to pursue less human capital accumulation in period 1 , even if that particular variable should also increase the productivity of human capital in production. In particular, we can conclude from our three-factor model that:

Proposition $5 \frac{\partial H}{\partial T}<0:$ A country with a higher land endowment will invest less in human capital.

Proof. Follows immediately from (18) and (12).

It is worth stressing that while the connection between aggregate political participation and human capital provision in the model is very tight, this does not mean that the model implies any type of correlation between observed political participation and equilibrium levels of human capital. This is because the ruler can use his period-1 choice over $H$ to compensate for any variables that might otherwise increase $X$ in period 2. As a result, we need not expect any particular correlation between measures of political participation at the aggregate level and our variables of interest, such as the per worker land endowment: The latter's impact can be neutralized by the ruler's choice of human capital level. In fact, going back to our motivating comparison between East Asia and Latin America, this helps us to rationalize a situation where countries with much higher levels of education do not necessarily display higher levels of aggregate political participation.

A further implication, seen from putting (16) and (17) together, is that the equilibrium choices of $H$ and $K$ are positively correlated, since both $F_{H}(\cdot)$ and $F_{K}(\cdot)$ exhibit decreasing returns. The intuition is as follows: A high $K$ will lead the ruler to increase production by raising $H$, as further increases to $K$ will be relatively costly given the concave nature of the $F_{K}(\cdot)$ function.

In sum, our model predicts that aggregate political participation, and the underlying variables that affect it, will play a crucial role in determining the level of human capital that will be provided by a nondemocratic ruler. More specifically, we have two predictions about the level of human capital accumulation across nondemocratic countries: Schooling increases should be negatively correlated with a country's initial land endowment, and positively correlated with the level of physical capital.

\subsection{Factor Endowments and Schooling Gains in the Cross-Country Data}

We offer some suggestive evidence that the human capital accumulation experiences of countries in recent decades is consistent with the predictions of our model regarding how much rulers would choose to invest in educating the citizenry. To this end, we use the Barro-Lee (2000) data on years of education attainment 
in the population aged 15 and over. In our regressions in Table 5, we focus on the change in average years of schooling between 1975 and 2000 as our key dependent variable. We examine whether: (i) the initial factor endowment attributes of the country affect future human capital accumulation paths; and whether (ii) this relationship between increases in schooling and initial factor endowments depends on the initial level of democracy.

\section{[TABLE 5 HERE]}

We find evidence that is remarkably consistent with our theoretical discussion in the previous subsection. In all the regressions in Table 5, we include initial years of schooling in 1975 to capture possible convergence effects in the data, but our focus is really on the other explanatory variables. Column (1) demonstrates that the initial level of democracy in 1975 (as measured on a 0-10 scale in the Polity IV dataset) does not provide much explanatory power for increases in the total years of schooling for citizens over the next quarter-century. The addition of the initial endowment of Log arable land per worker in Column (2) does not improve the regression much. Interestingly, once we further include in Column (3) an interaction term between initial democracy and initial $\log (T / L)$, we find a negative and significant level effect of land abundance on subsequent increases in schooling, as a well as a positive and significant effect on the interaction term: Countries well endowed in land (relative to labor) witnessed smaller increases in schooling, and this effect was more pronounced for less democratic countries (with a low Polity score).

Column (4) considers the level effects of initial Log arable land per worker and initial Log physical capital stock per worker, without considering interaction effects. The results suggest that a higher initial physical capital stock is associated with larger increases in education, which is indicative of some complementarity between physical and human capital in a country's development. Column (5) adds the interaction terms involving initial democracy, with initial $\log (T / L)$ and $\log (K / L)$. The level effect of the land-labor ratio is now marginally insignificant at the $10 \%$ level, even though the sign remains negative. The interaction effect between land abundance and democracy remains positive and significant. Of somewhat more interest, we continue to find a positive and significant level correlation with initial physical capital abundance, but a negative and significant interaction effect between initial physical capital abundance and democracy. In other words, countries which were initially well endowed in physical capital pursued larger increases in schooling, but this effect was smaller in democracies than in nondemocracies. This is loosely consistent with our model's prediction of a positive correlation between physical and human capital; moreover, it dovetails with popular accounts of development paths pursued in the East Asian economies, where strong leaders were able to harness resources towards a growth strategy driven by both physical and human capital accumulation.

Column (6) re-runs the specification in Column (5), but removing countries that are potential outliers (more than three standard deviations away from the sample mean) in terms of their initial factor 
endowments. This takes out three countries with especially low land-labor ratios (Bahrain, Kuwait and Singapore). This in fact strengthens the statistical significance of our results; in particular, the level effect of the initial relative land endowment is now negative and significant at the $5 \%$ level. In Columns (7)-(9), we investigate which component of schooling - primary, secondary, or higher (post-secondary) - might be driving our results based on total years of schooling. We run the Column (6) specification using each of these finer measures of schooling instead. The negative level effect of land abundance and its positive interaction effect with initial democracy appear most significant in the regressions run with secondary and higher years of schooling (Columns (8) and (9)). This is consistent with the view that it is citizens with secondary or post-secondary levels of education who are more likely to participate in political activities. Consequently, the decision to provide access to these higher levels of education is more sensitive to the initial land endowment.

In short, the data at the cross-country level suggest that initial factor endowments matter in determining subsequent human capital accumulation paths, and that the nature of this relationship depends on whether countries were initially democratic or non-democratic.

\section{Conclusion}

We have developed a framework that sheds light on the link between schooling and political participation, by stressing how this link will be shaped at the individual level by country variables, such as factor endowments, that affect the relative productivity of human capital in political versus production activities. This enables us to add to the empirical evidence on the determinants of political participation, by exploiting the interaction between individual- and country-level data.

We find that a higher per worker land endowment tends to strengthen the positive correlation between schooling and individual political participation, while a higher economy-wide human capital endowment tends to weaken it instead. We argue that this evidence is consistent with a model in which individuals face a decision to allocate their limited human capital between various production activities (that yield personal income) and political activities (that constrain the ability of the ruler to tax or expropriate). In countries where the underlying factor endowment mix is more land-abundant, and hence more skewed towards the least skill-intensive sector, individuals will rationally allocate any additional human capital towards political participation. Conversely, when the economy sports a higher human capital endowment, individuals will tend to divert additional human capital away from political activities towards skillintensive production activities instead. We have also shown how the same framework can be extended to help us understand how initial endowment conditions can affect the different paths in terms of human capital accumulation that various countries have pursued.

It is worth noting that while we focus on factor endowments, for which it is relatively easy to provide empirical content, our neoclassical approach generalizes to other economic, political or social variables 
that affect the relative productivity of human capital in production versus politics. For instance, one could think that the presence of natural resources whose exploitation is not intensive in human capital would have similar consequences to those of a greater land endowment in our model. This could be useful in understanding the choices of many countries with regard to the accumulation of human capital, and in fact could be interpreted as yet another manifestation of the "natural resource curse": The abundance of natural resources could hinder growth by discouraging governments from investing in human capital for fear of breeding political activism, particularly in nondemocratic countries.

It should be stressed that we view our framework as in fact complementary to other explanations raised in this debate that are based on cultural values and political institutions. This is apparent from our empirical results, in which we emphasize that country-level variables of that nature (respectively, compulsory voting laws and measures of attitudes towards obedience) are also important in understanding the individual link between schooling and political participation. Nevertheless, we believe there is promise in investigating how variables such as factor endowments or other initial conditions can help us understand how such cultural and institutional elements themselves arise and are sustained in equilibrium. We leave this line of questioning for future research.

In sum, our model illuminates the connections between education and political participation both at the individual and at the country levels. We believe this interaction is fertile ground for future research, both theoretical and empirical. 


\section{References}

Acemoglu, Daron (2005), "Politics and Economics in Weak and Strong States," Journal of Monetary Economics 52: 1199-1226.

Acemoglu, Daron, Simon Johnson, and James Robinson (2002), "Reversal of Fortune: Geography and Institutions in the Making of the Modern World Income Distribution," Quarterly Journal of Economics 118: 1231-1294.

Acemoglu, Daron, Simon Johnson, James Robinson, and Pierre Yared (2005), "From Education to Democracy?" American Economic Review Papers and Proceedings 95: 44-49.

Acemoglu, Daron, Simon Johnson, James Robinson, and Pierre Yared (2007), "Revaluating the Modernization Hypothesis," NBER Working Paper No. 13334.

Acemoglu, Daron, Simon Johnson, James Robinson, and Pierre Yared (2008), "Income and Democracy," American Economic Review 98: 808-842.

Aldrich, John A. (1993), "Rational Choice and Turnout," American Journal of Political Science 37: 246-278.

Alesina, Alberto, Arnaud Devleeschauwer, William Easterly, Sergio Kurlat, and Romain Wacziarg (2003), "Fractionalization", Journal of Economic Growth 8: 155-194.

Barro, Robert, and Lee Jong Wha (2000), "International Data on Educational Attainment: Updates and Implications," Harvard Center for International Development, Working Paper no. 42.

Bénabou, Roland (2000), "Unequal Societies: Income Distribution and the Social Contract," American Economic Review 90: 96-129.

Birdsall, Nancy, Barbara Bruns, and Richard H. Sabot (1996), "Education in Brazil: Playing a Bad Hand Badly." In Nancy Birdsall and Richard H. Sabot, eds. Opportunity Foregone: Education in Brazil, Washington, DC: Johns Hopkins Press for the Inter-American Development Bank.

Bobba, Matteo, and Decio Coviello (2007), "Weak Instruments and Weak Identification, in Estimating the Effects of Education, on Democracy," Economic Letters 96: 301-307.

Bourguignon, François, and Thierry Verdier (2000), "Oligarchy, Democracy, Inequality and Growth," Journal of Development Economics 62: 285-313.

Brady, Henry E. Sidney Verba, and Kay Lehman Schlozman (1995), "Beyond SES: A Resource Model of Political Participation," American Political Science Review 89: 271-294.

Brody, Richard A. (1978), "The Puzzle of Political Participation in America." In: Anthony King (ed.), The New American Political System, Washington DC: American Enterprise Institute.

Brown, David S. (2002), "Democracy, Authoritarianism and Education Finance in Brazil," Journal of Latin American Studies 34: 115-141.

Caselli, Francesco (2005), "Accounting for Cross-Country Income Differences." In Philippe Aghion and Steven Durlauf, eds. Handbook of Economic Growth, Amsterdam: North-Holland.

Castelló-Climent, Amparo (2008), "On the Distribution of Education and Democracy," Journal of Development Economics 87: 179-190.

Dal Bó, Ernesto, and Pedro Dal Bó (2004), "Workers, Warriors and Criminals: Social Conflict in General Equilibrium," Brown University mimeo.

Dee, Thomas (2004), "Are there Civic Returns to Education?" Journal of Public Economics 88: 16971720. 
De la Croix, David, and Matthias Doepke (2008), "To Segregate or to Integrate: Education Politics and Democracy," forthcoming in Review of Economic Studies.

Dewey, John (1916), Democracy and Education, New York: The Macmillan Company.

Diermeier, Daniel, Michael Keane, and Antonio Merlo (2005), "A Political Economy Model of Congressional Careers," American Economic Review 95: 347-373.

Engerman, Stanley L. and Kenneth L. Sokoloff (1997), "Factor Endowments, Institutions, and Differential Paths of Growth Among New World Economies: A View from Economic Historians of the United States." In Stephen Haber, ed. How Latin America Fell Behind, California: Stanford University Press.

Freeman, Richard B. (2004), "What, Me Vote?" In Social Inequality, New York: Russell Sage Foundation, 703-728.

Galiani, Sebastian, Daniel Heymann, Carlos Dabús, and Fernando Tohmé (2008), "On the emergence of public education in land-rich economies," Journal of Development Economics 86: 434-446.

Galor Oded, and Omer Moav (2006), "Das Human Kapital: A Theory of the Demise of the Class Structure," Review of Economic Studies 73: 85-117.

Galor Oded, Omer Moav, and Dietrich Vollrath (2008), "Inequality in Land Ownership, the Emergence of Human Capital Promoting Institutions and the Great Divergence," forthcoming in Review of Economic Studies.

Glaeser, Edward, Rafael La Porta, Florencio López-de-Silanes, and Andrei Shleifer (2004), "Political Institutions and Human Capital in Economic Development," Journal of Economic Growth 9: 271303.

Glaeser, Edward L, Giacomo Ponzetto, and Jesse Shapiro (2005), "Strategic Extremism: Why Republicans and Democrats Divide on Religious Values," Quarterly Journal of Economics 120: 1283-1330.

Glaeser, Edward, Giacomo Ponzetto, and Andrei Shleifer (2007), "Why does Democracy Need Education?" Journal of Economic Growth 12: 77-99.

Hall, Robert, and Charles Jones (1999), "Why Do Some Countries Produce So Much More Output Per Worker Than Others?" Quarterly Journal of Economics 114: 83-116.

Heston, Alan, Robert Summers, and Bettina Aten (2006), "Penn World Table Version 6.2", Center for International Comparisons of Production, Income and Prices at the University of Pennsylvania.

Huntington, Samuel P. (1991), "Democracy's Third Wave" Journal of Democracy 2: 12-34.

La Porta, R., Lopez-de-Silanes, F., Shleifer, A., Vishny, R. (1999), "The Quality of Government", Journal of Law, Economics and Organization 15: 222-279.

Leamer, Edward E., Hugo Maúl, Sergio Rodríguez, and Peter K. Schott (1999), "Does Natural Resource Abundance Increase Latin American Income Inequality?" Journal of Development Economics 59: $3-42$.

Lee, Jong Wha, and Sun-Bin Kim (1997), "Estimates of Human Capital Stock in Korea, 1963-1993," Korea Social Science Journal 23: 73-102.

Lipset, Seymour (1959), "Some Social Requisites of Democracy: Economic Development and Political Legitimacy," American Political Science Review 53: 69-105.

Milligan, Kevin, Enrico Moretti, and Philip Oreopoulos (2004), "Does education improve citizenship? Evidence from the United States and the United Kingdom," Journal of Public Economics 88: 1667-1695. 
Milner, Anthony (2000), "What Happened to 'Asian Values'?" In Gerald Segal and David Goodman (eds.), Towards Recovery in Pacific Asia, London and New York: Routledge.

Murphy, Kevin M., Andrei Shleifer, and Robert Vishny (1991), "Allocation of Talent: Implications for Growth," Quarterly Journal of Economics 106: 503-530.

Naritomi, Joana, Rodrigo R. Soares, and Juliano J. Assunção (2007), "Rent Seeking and the Unveiling of De Facto Institutions: Development and Colonial Heritage within Brazil," University of Maryland mimeo.

North, Douglass (1990), Institutions, Institutional Change and Economic Performance, Cambridge, UK: Cambridge University Press.

Pritchett, Lant (2001), "Where Has All the Education Gone?" World Bank Economic Review 15: 367-391.

Pritchett, Lant (2003), "When Will They Ever Learn? Why All Governments Produce Schooling", BREAD working paper \# 31 .

Putnam, Robert D. (1995a), "Bowling Alone: America's Declining Social Capital," Journal of Democracy 6: 65-78.

Putnam, Robert D. (1995b), "Tuning In, Tuning Out: The Strange Disappearance of Social Capital in America," PS: Political Science \& Politics 28: 664-683.

Ratliff, William (2003), "Doing it Wrong and Doing it Right: Education in Latin America and Asia", Hoover Institution, Essays in Public Policy n. 110.

Rosenstone, Steven J. and John M. Hansen (1993), Mobilization, Participation and Democracy in America, New York: MacMillan.

Solt, Frederick (2008), "Economic Inequality and Democratic Political Engagement," American Journal of Political Science 52: 48-60.

Verba, Sidney, and Norman H. Nie (1987), Participation in America: Political Democracy and Social Equality, Chicago, IL: University of Chicago Press.

Verba, Sidney, Norman H. Nie, and Jae-On Kim (1987), Participation and Political Equality: A SevenNation Comparison, Chicago, IL: University of Chicago Press.

Wynia, Gary W. (1978), The Politics of Latin American Development, Cambridge, UK: Cambridge University Press.

Zhang, Lei (2008), "Political Economy of Income Distribution Dynamics," Journal of Development Economics 87: 119-139. 


\section{Data Appendix}

\section{Individual characteristics:}

World Values Survey (WVS): All four available waves were cleaned and merged by ASEP/JDS, in collaboration with Tilburg University and Khöln Zentral Archiv. Data available at: http://www.jdsurvey.net/jds/jdsurvey.jsp. The various measures of political participation used are described in the main text (Section 3.2). For the key explanatory variable (education), we use question X025, which asks respondents for their highest educational level attained; the answers range from $1=$ 'Inadequately completed elementary education' to $8=$ 'University with degree/Higher education - upper-level tertiary certificate'.

Comparative Study of Electoral Systems (CSES): From http://www.cses.org/. Modules 1 and 2 were merged. The voting variable is based on questions A2028 in Module 1 and B3004_1 in Module 2, recoded so that 1 indicates the respondent voted at the election in question, and 0 that he/she did not voted. We set this variable to missing for a very small number of respondents whose answers exhibited inconsistencies, namely (i) respondents who said they did not vote but nevertheless indicated on a later question a party for which they voted; and (ii) respondents who said they voted, but did not name a party for which they voted. The education variable is from questions A2003 and B2003 in Modules 1 and 2 respectively, coded on a scale of 1-8 (ranging from $1=$ 'None' to $8=$ 'University undergraduate degree completed'; this is a slightly different coding from the WVS, but nevertheless largely comparable). The indicator variable for compulsory voting is based on questions A5031 and B5037 in Modules 1 and 2 respectively. We recode these variables to equal 0 if there are no compulsory voting laws, and 1 if such laws exist.

\section{Country-level variables:}

Arable land per worker, $\log (T / L)$ : From the World Development Indicators (WDI). Computed as the hectares of arable land divided by the population between ages 15-64.

Physical capital per worker, $\log (K / L)$ : Physical capital stock is calculated using the perpetual inventory method, namely: $K_{t}=I_{t}+\delta K_{t-1}$, where $I_{t}$ is investment and $\delta=0.06$ is the assumed depreciation rate. The investment flow data are from the Penn World Tables, Version 6.2 (Heston et al. 2006). The initial capital stock, $K_{0}$, is taken as $I_{0} /(g+\delta)$, where $I_{0}$ is the earliest value of investment available. $g$ is the average geometric growth rate of investment in the first 10 years for which the investment data are available. Countries with less than 20 years of investment flow data are dropped, since the assumed initial value for $K_{0}$ has a larger effect when the available time series is too short. This means that only countries with investment data since 1970 are included, which in practice only drops the transition economies in Eastern Europe.

Human capital per worker, $\log (H / L)$ : From Caselli (2005). Calculated as the average years of schooling in the country, weighted by the Mincerian returns to education. Specifically, $H / L=$ $\exp (\phi(s))$, where $s$ is the average years of schooling in the population over 25 years of age, and $\phi(\cdot)$ is a piece-wise linear function with a slope of 0.13 for $s<4,0.10$ for $4<s<8$, and 0.07 for $s>8$. This follows Hall and Jones (1999): The first slope of 0.13 corresponds to the average Mincerian return to education observed in sub-Saharan Africa, the second slope of 0.10 corresponds to the average return for the world, while the third slope of 0.07 corresponds to the average return in the OECD.

Years of schooling: From the Barro and Lee (2000) dataset. 
GDP per capita: From the WDI. Real GDP per capita in constant 2000 US dollars.

Population: From the WDI. Population between ages 15-64.

Gini coefficients: From the World Income Inequality Database (WIID), version 2.0, assembled by the World Institute of Development Economic Research (WIDER). We use the income gini coefficients ("incdefn" code equal to "Earnings, Gross", "Income, Factor", "Income, Gross", "Income, Taxable", "Market Income", "Monetary Income, Gross", "Earnings, Net", "Income, Disposable", or "Monetary Income, Disposable"). We use only those data points identified by the WIID as being of reasonably good quality (quality code equal to 1 or 2 ).

Democracy: From the Polity IV dataset. Democracy score, on a scale of 0 to 10. The reference date for the annual observations in the Polity IV dataset is 31 December. We match these to the data corresponding to 1 January of the following year.

Socialist: From La Porta et al. (1999). Dummy variable equal to 1 if country is of socialist legal origin.

Ethnic Fractionalization: From Alesina et al. (2003). Equal to 1 minus the Herfindahl Index of population shares of ethnic groups within a country. This is treated as a state variable that does not vary over time. 


\section{Appendix (Proofs)}

\section{Proof of Proposition 1}

Proof. The existence of a solution to the effort-allocation problem is guaranteed by the fact that the maximand (4) is a continuous function over the compact simplex defined by (5) and the non-negativity constraints. Now, substitute $x=H-h_{A}-h_{M}-h_{S}$ into (4). Treating this as an unconstrained maximization problem, the first-order conditions with respect to $h_{A}, h_{M}$, and $h_{S}$ jointly imply that:

$$
\alpha h_{A}^{\alpha-1} T^{1-\alpha}=\mu p_{M} A_{M} h_{M}^{\mu-1} K^{1-\mu}=\sigma p_{S} A_{S} h_{S}^{\sigma-1} S^{1-\sigma}
$$

and also that:

$$
(1-\tau(X)) \alpha h_{A}^{\alpha-1} T^{1-\alpha}=-\tau^{\prime}(X)\left[h_{A}^{\alpha} T^{1-\alpha}+\frac{\alpha}{\mu} h_{A}^{\alpha-1} T^{1-\alpha} h_{M}+\frac{\alpha}{\sigma} h_{A}^{\alpha-1} T^{1-\alpha} h_{S}\right],
$$

This last equation can be rewritten as:

$$
-\frac{1-\tau(X)}{\tau^{\prime}(X)}=\left[\frac{1}{\alpha} h_{A}+\frac{1}{\mu} h_{M}+\frac{1}{\sigma} h_{S}\right] .
$$

The assumption that $\tau^{\prime}(0) \longrightarrow-\infty$ and the Cobb-Douglas production functions (which satisfy a similar Inada condition), ensure that the non-negativity constraints do not bind in practice, since the infinite marginal product in a neighborhood of zero guarantees that it is optimal to allocate a positive amount of effort to every activity. Thus, the first-order conditions above from the unconstrained maximization problem also pin down the solution to the constrained problem.

Differentiating (19) yields:

$$
\frac{d h_{A}}{d H}=\frac{1-\mu}{1-\alpha} \frac{h_{A}}{h_{M}} \frac{d h_{M}}{d H}=\frac{1-\sigma}{1-\alpha} \frac{h_{A}}{h_{S}} \frac{d h_{S}}{d H}
$$

while differentiating (20) yields:

$$
\Theta \frac{d x}{d H}=\frac{1}{\alpha} \frac{d h_{A}}{d H}+\frac{1}{\mu} \frac{d h_{M}}{d H}+\frac{1}{\sigma} \frac{d h_{S}}{d H}
$$

where $\Theta \equiv\left[1+\frac{1-\tau}{\tau^{\prime}} \frac{\tau^{\prime \prime}}{\tau^{\prime}}\right]$. Since $\tau^{\prime}<0$ and $\tau^{\prime \prime}>0$, this implies that $\Theta \geq 0$. Finally, differentiating the budget constraint (5) yields:

$$
\frac{d h_{A}}{d H}+\frac{d h_{M}}{d H}+\frac{d h_{S}}{d H}+\frac{d x}{d H}=1
$$

Based on (21), we know that $\frac{d h_{A}}{d H}, \frac{d h_{M}}{d H}$ and $\frac{d h_{S}}{d H}$ share the same sign (since $0<\alpha, \mu, \sigma<1$ ). In addition, (22) implies that $\frac{d x}{d H}$ also shares this same sign because $\Theta \geq 0$. It immediately follows from (23) that this sign has to be positive.

\section{Proof of Proposition 2}


Proof. Part 1. We proceed in a similar fashion to the proof of Proposition 1, to set up a system of four equations in $\frac{d h_{A}}{d T}, \frac{d h_{M}}{d T}, \frac{d h_{S}}{d T}$, and $\frac{d x}{d T}$. To do so, we totally differentiate (5), (19), and (20) with respect to $T$. The analogue of equation (21) is now:

$$
\begin{gathered}
\frac{d h_{A}}{d T}=\frac{h_{A}}{T}+\frac{1-\mu}{1-\alpha} \frac{h_{A}}{h_{M}} \frac{d h_{M}}{d T}, \\
\frac{1-\mu}{h_{M}} \frac{d h_{M}}{d T}=\frac{1-\sigma}{h_{S}} \frac{d h_{S}}{d T} .
\end{gathered}
$$

Also, (22) remains unchanged, except that all derivatives with respect to $H$ should be replaced by derivatives with respect to $T$. Finally, the constraint (5) now implies:

$$
\frac{d h_{A}}{d T}+\frac{d h_{M}}{d T}+\frac{d h_{S}}{d T}+\frac{d x}{d T}=0
$$

Substituting $\frac{d x}{d T}$ from (26) into the new version of (22) yields:

$$
\frac{d h_{A}}{d T}=\frac{1}{D_{T}}\left[\left(\frac{1}{\mu}+\Theta\right) \frac{1-\alpha}{1-\mu} \frac{h_{M}}{T}+\left(\frac{1}{\sigma}+\Theta\right) \frac{1-\alpha}{1-\sigma} \frac{h_{S}}{T}\right]>0,
$$

where we define $D_{T} \equiv\left(\frac{1}{\alpha}+\Theta\right)+\left(\frac{1}{\mu}+\Theta\right) \frac{1-\alpha}{1-\mu} \frac{h_{M}}{h_{A}}+\left(\frac{1}{\sigma}+\Theta\right) \frac{1-\alpha}{1-\sigma} \frac{h_{S}}{h_{A}}$ to keep notation simple. Substituting this into (24) in turn yields:

$$
\frac{d h_{M}}{d T}=\frac{1}{D_{T}}\left[\frac{1-\alpha}{1-\mu} \frac{h_{M}}{h_{A}}\left[\left(\frac{1}{\mu}+\Theta\right) \frac{1-\alpha}{1-\mu} \frac{h_{M}}{T}+\left(\frac{1}{\sigma}+\Theta\right) \frac{1-\alpha}{1-\sigma} \frac{h_{S}}{T}\right]-D_{T} \frac{1-\alpha}{1-\mu} \frac{h_{M}}{T}\right],
$$

which, with some straightforward manipulation, we can turn into:

$$
\frac{d h_{M}}{d T}=-\frac{1}{D_{T}} \frac{1-\alpha}{1-\mu} \frac{h_{M}}{T}\left[\frac{1}{\alpha}+\Theta\right]<0 .
$$

Note that (25) now immediately implies that $\frac{d h_{S}}{d T}<0$, since it must have the same sign as $\frac{d h_{M}}{d T}$. In fact, we can pin down:

$$
\frac{d h_{S}}{d T}=-\frac{1}{D_{T}} \frac{1-\alpha}{1-\sigma} \frac{h_{S}}{T}\left[\frac{1}{\alpha}+\Theta\right]<0
$$

Now we can substitute into (26) the expressions for $\frac{d h_{A}}{d T}, \frac{d h_{M}}{d T}$, and $\frac{d h_{S}}{d T}$ that we have just obtained. This yields:

$$
\frac{d x}{d T}=-\frac{1}{D_{T}}\left[\frac{1-\alpha}{1-\mu} \frac{h_{M}}{T}\left(\frac{1}{\mu}-\frac{1}{\alpha}\right)+\frac{1-\alpha}{1-\sigma} \frac{h_{S}}{T}\left(\frac{1}{\sigma}-\frac{1}{\alpha}\right)\right] .
$$

Our assumptions that $0<\alpha<\mu<\sigma<1$ imply that the terms in brackets are negative, hence $\frac{d x}{d T}>0$.

Part 2. We proceed in an analogous fashion as in the proof of Part 1. All one has to note is that the role played by $h_{A}$ in Part 1 is now played by $h_{M}$, and we should replace the parameters suitably as well; what used to be $\alpha$ is now $\mu$, and vice-versa. Once this is done, it is easy to check that $\frac{d h_{M}}{d K}>0$ (just as $\frac{d h_{A}}{d T}>0$ ), $\frac{d h_{A}}{d K}<0$, and $\frac{d h_{S}}{d K}<0$. We can also see why the sign of $\frac{d x}{d K}$ is ambiguous: $\frac{1}{\alpha}-\frac{1}{\mu}>0$, while $\frac{1}{\sigma}-\frac{1}{\alpha}<0$. 
Part 3. A similar analogy goes for this part, with $h_{S}$ and $\sigma$ replacing $h_{M}$ and $\mu$, respectively, in our description of Part 2. It immediately follows that $\frac{d h_{S}}{d S}>0, \frac{d h_{A}}{d S}<0$, and $\frac{d h_{M}}{d S}<0$. Now the sign of $\frac{d x}{d S}$ is negative, since $\frac{1}{\alpha}-\frac{1}{\sigma}>0$, and $\frac{1}{\mu}-\frac{1}{\sigma}>0$.

\section{Proof of Proposition 3}

Proof. Substituting (21) into (22) and (23), we obtain:

$$
\frac{d x}{d H}=\frac{1}{1+\Theta \Lambda},
$$

where $\Lambda \equiv\left[\frac{\frac{1}{1-\alpha} h_{A}+\frac{1}{1-\mu} h_{M}+\frac{1}{1-\sigma} h_{S}}{\frac{1}{\alpha} \frac{1}{1-\alpha} h_{A}+\frac{1}{\mu} \frac{1}{1-\mu} h_{M}+\frac{1}{\sigma} \frac{1}{1-\sigma} h_{S}}\right]$. It follows that the sign of $\frac{d^{2} x}{d H d T}$ depends on $\frac{d \Theta}{d T}$ and $\frac{d \Lambda}{d T}$. Our functional form assumption on $\tau(X)$ simplifies the problem as $\Theta$ is a positive constant. We can thus conclude that the sign of $\frac{d^{2} x}{d H d T}$ will be the opposite of the sign of $\frac{d \Lambda}{d T}$.

We proceed to obtain the sign of $\frac{d \Lambda}{d T}$. We start by noting that:

$$
\begin{aligned}
\frac{d \Lambda}{d T} \propto[ & \left.\left(\frac{1}{\mu}-\frac{1}{\alpha}\right) \frac{1}{1-\mu} h_{M}+\left(\frac{1}{\sigma}-\frac{1}{\alpha}\right) \frac{1}{1-\sigma} h_{S}\right] \frac{1}{1-\alpha} \frac{d h_{A}}{d T} \\
& +\left[\left(\frac{1}{\alpha}-\frac{1}{\mu}\right) \frac{1}{1-\alpha} h_{A}+\left(\frac{1}{\sigma}-\frac{1}{\mu}\right) \frac{1}{1-\sigma} h_{S}\right] \frac{1}{1-\mu} \frac{d h_{M}}{d T} \\
& +\left[\left(\frac{1}{\alpha}-\frac{1}{\sigma}\right) \frac{1}{1-\alpha} h_{A}+\left(\frac{1}{\mu}-\frac{1}{\sigma}\right) \frac{1}{1-\mu} h_{M}\right] \frac{1}{1-\sigma} \frac{d h_{S}}{d T}
\end{aligned}
$$

Given the parameter assumption $0<\alpha<\mu<\sigma<1$, and the signs of the derivatives from Proposition 2 , all of the terms in the expression above are negative, except for the term $\left(\frac{1}{\sigma}-\frac{1}{\mu}\right) \frac{1}{1-\sigma} h_{S} \frac{1}{1-\mu} \frac{d h_{M}}{d T}$. However, collecting the two terms involving $\left(\frac{1}{\sigma}-\frac{1}{\mu}\right)$ and using (25), we obtain:

$$
\left(\frac{1}{\sigma}-\frac{1}{\mu}\right) \frac{1}{(1-\sigma)(1-\mu)}\left[h_{S} \frac{d h_{M}}{d T}-h_{M} \frac{d h_{S}}{d T}\right]=\left(\frac{1}{\sigma}-\frac{1}{\mu}\right) \frac{\mu-\sigma}{(1-\sigma)(1-\mu)} h_{M} \frac{d h_{S}}{d T}<0 .
$$

It follows that $\frac{d \Lambda}{d T}<0$, and hence $\frac{d^{2} x}{d H d T}>0$.

A similar approach can be taken to sign the cross derivative with respect to $H$ and $S$. We have an expression for $\frac{d \Lambda}{d S}$ that mirrors (28), the only difference being that $T$ is replaced by $S$. The proof of Proposition 2 yields expressions for $\frac{d h_{A}}{d S}, \frac{d h_{M}}{d S}$, and $\frac{d h_{S}}{d S}$, and we plug these into the expression for $\frac{d \Lambda}{d S}$ that follows from (28). This yields:

$$
\begin{aligned}
\frac{d \Lambda}{d S} \propto- & {\left[\left(\frac{1}{\mu}-\frac{1}{\alpha}\right) \frac{1}{1-\mu} h_{M}+\left(\frac{1}{\sigma}-\frac{1}{\alpha}\right) \frac{1}{1-\sigma} h_{S}\right] \frac{1}{1-\alpha} \frac{1}{D_{S}}\left(\frac{1}{\sigma}+\Theta\right) \frac{1-\sigma}{1-\alpha} \frac{h_{A}}{S}-} \\
& -\left[\left(\frac{1}{\alpha}-\frac{1}{\mu}\right) \frac{1}{1-\alpha} h_{A}+\left(\frac{1}{\sigma}-\frac{1}{\mu}\right) \frac{1}{1-\sigma} h_{S}\right] \frac{1}{1-\mu} \frac{1}{D_{S}}\left(\frac{1}{\sigma}+\Theta\right) \frac{1-\sigma}{1-\mu} \frac{h_{M}}{S}+ \\
+ & {\left[\left(\frac{1}{\alpha}-\frac{1}{\sigma}\right) \frac{1}{1-\alpha} h_{A}+\left(\frac{1}{\mu}-\frac{1}{\sigma}\right) \frac{1}{1-\mu} h_{M}\right] \frac{1}{1-\sigma} \frac{1}{D_{S}}\left[\left(\frac{1}{\alpha}+\Theta\right) \frac{1-\sigma}{1-\alpha} \frac{h_{A}}{S}+\left(\frac{1}{\mu}+\Theta\right) \frac{1-\sigma}{1-\mu} \frac{h_{M}}{S}\right] }
\end{aligned}
$$

Some further simplification yields: 


$$
\begin{aligned}
\frac{d \Lambda}{d S} \propto- & \left(\frac{1}{1-\alpha}\right)^{2}\left[\left(\frac{1}{\mu}-\frac{1}{\alpha}\right) \frac{1}{1-\mu} h_{M}+\left(\frac{1}{\sigma}-\frac{1}{\alpha}\right) \frac{1}{1-\sigma} h_{S}\right] h_{A}- \\
& -\left(\frac{1}{1-\mu}\right)^{2}\left[\left(\frac{1}{\alpha}-\frac{1}{\mu}\right) \frac{1}{1-\alpha} h_{A}+\left(\frac{1}{\sigma}-\frac{1}{\mu}\right) \frac{1}{1-\sigma} h_{S}\right] h_{M}+ \\
& +\frac{1}{1-\sigma}\left[\left(\frac{1}{\alpha}-\frac{1}{\sigma}\right) \frac{1}{1-\alpha} h_{A}+\left(\frac{1}{\mu}-\frac{1}{\sigma}\right) \frac{1}{1-\mu} h_{M}\right]\left[\frac{\frac{1}{\alpha}+\Theta}{\frac{1}{\sigma}+\Theta} \frac{h_{A}}{1-\alpha}+\frac{\frac{1}{\mu}+\Theta}{\frac{1}{\sigma}+\Theta} \frac{h_{M}}{1-\mu}\right] .
\end{aligned}
$$

The terms in (30) involving $h_{A} h_{S}$ and $h_{M} h_{S}$ are all unambiguously positive. Moreover, we can collect all terms in $h_{A} h_{M}$, which are proportional (up to a positive multiplicative constant) to:

$$
\begin{aligned}
& \frac{1}{1-\alpha}\left(\frac{1}{\alpha}-\frac{1}{\mu}\right)-\frac{1}{1-\mu}\left(\frac{1}{\alpha}-\frac{1}{\mu}\right)+\frac{1}{1-\sigma}\left[\left(\frac{1}{\mu}-\frac{1}{\sigma}\right) \frac{\frac{1}{\alpha}+\Theta}{\frac{1}{\sigma}+\Theta}+\left(\frac{1}{\alpha}-\frac{1}{\sigma}\right) \frac{\frac{1}{\mu}+\Theta}{\frac{1}{\sigma}+\Theta}\right] \\
> & \frac{1}{1-\alpha}\left(\frac{1}{\alpha}-\frac{1}{\mu}\right)-\frac{1}{1-\mu}\left(\frac{1}{\alpha}-\frac{1}{\mu}\right)+\frac{1}{1-\sigma}\left[\left(\frac{1}{\mu}-\frac{1}{\sigma}\right)+\left(\frac{1}{\alpha}-\frac{1}{\sigma}\right)\right] \\
> & 0 .
\end{aligned}
$$

This last inequality follows from the parameter restriction $0<\alpha<\mu<\sigma<1$, which in turn ensures that:

$$
\frac{1}{1-\mu}\left(\frac{1}{\alpha}-\frac{1}{\mu}\right)<\frac{1}{1-\sigma}\left(\frac{1}{\alpha}-\frac{1}{\sigma}\right)
$$

Thus, we can conclude that $\frac{d \Lambda}{d S}>0$, from which it follows that $\frac{d^{2} x}{d H d S}<0$.

We can repeat the same exercise for $\frac{d \Lambda}{d K}$. This will yield an analogous equation to (28) with $T$ replaced by $K$, in which the term in $\frac{d h_{A}}{d K}$ is positive, but the term in $\frac{d h_{S}}{d K}$ is negative, and the term in $\frac{d h_{M}}{d K}$ is again of an ambiguous sign. It turns out that this configuration implies an ambiguous sign for $\frac{d^{2} x}{d H d K}$.

\section{Proof of Proposition 4}

Proof. Manipulating (19) yields:

$$
\begin{gathered}
h_{M}=\left(\frac{\mu}{\alpha} A_{M} p_{M}\right)^{\frac{1}{1-\mu}}\left(\frac{h_{A}}{T}\right)^{\frac{1-\alpha}{1-\mu}} K, \\
h_{S}=\left(\frac{\sigma}{\alpha} A_{S} p_{S}\right)^{\frac{1}{1-\sigma}}\left(\frac{h_{A}}{T}\right)^{\frac{1-\alpha}{1-\sigma}} S .
\end{gathered}
$$

Imposing symmetry $\left(h_{S}=S\right)$ on these two equations immediately implies:

$$
\begin{gathered}
h_{A}=\left(\frac{\alpha}{\sigma A_{S} p_{S}}\right)^{\frac{1}{1-\alpha}} T, \\
h_{M}=\left(\frac{\mu A_{M} p_{M}}{\sigma A_{S} p_{S}}\right)^{\frac{1}{1-\mu}} K .
\end{gathered}
$$


Now we can use the functional form for $\tau(X)$ in (20), and (5), to obtain:

$$
\begin{aligned}
& \frac{N x}{\sigma_{x}}=\frac{1}{\alpha} h_{A}+\frac{1}{\mu} h_{M}+\frac{1}{\sigma} h_{S} \\
\Rightarrow \quad & \frac{N}{\sigma_{x}}\left[H-h_{S}-h_{A}-h_{M}\right]=\frac{1}{\alpha} h_{A}+\frac{1}{\mu} h_{M}+\frac{1}{\sigma} h_{S} \\
\Rightarrow \quad & h_{S}=\frac{N \sigma}{\sigma_{x}+N \sigma} H-\frac{\sigma}{\alpha} \frac{N \alpha+\sigma_{x}}{N \sigma+\sigma_{x}} h_{A}-\frac{\sigma}{\mu} \frac{N \mu+\sigma_{x}}{N \sigma+\sigma_{x}} h_{M}
\end{aligned}
$$

Substituting this into (5) yields:

$$
x=\frac{\sigma_{x}}{\sigma_{x}+N \sigma} H+\frac{(\sigma-\alpha) \sigma_{x}}{\alpha\left(N \sigma+\sigma_{x}\right)} h_{A}+\frac{(\sigma-\mu) \sigma_{x}}{\mu\left(N \sigma+\sigma_{x}\right)} h_{M}
$$

The expression for $X$ follows immediately from the definition $X \equiv N x$. 
Table 1

Education and Political Participation in the WVS

\begin{tabular}{|c|c|c|c|c|c|c|c|}
\hline \multirow[t]{2}{*}{ Dependent variable: } & \multicolumn{7}{|c|}{ First Principal Component } \\
\hline & $(1)$ & $(2)$ & $(3)$ & (4) & (5) & (6) & $(7)$ \\
\hline \multirow[t]{2}{*}{ Education } & $0.166^{\star \star \star}$ & $0.183^{\star \star \star}$ & $0.189 * \star \star$ & 0.226 & $0.403^{*}$ & 0.306 & $0.352^{\star}$ \\
\hline & {$[0.008]$} & {$[0.035]$} & {$[0.036]$} & {$[0.215]$} & {$[0.199]$} & [0.192] & {$[0.185]$} \\
\hline \multirow[t]{2}{*}{ Education * $\log (\mathrm{T} / \mathrm{L})$} & & $0.021^{* * *}$ & $0.024^{* * *}$ & $0.025^{\star \star *}$ & $0.033^{* * *}$ & $0.028^{\star *}$ & $0.028^{\star *}$ \\
\hline & & {$[0.005]$} & {$[0.008]$} & {$[0.008]$} & {$[0.011]$} & {$[0.011]$} & {$[0.011]$} \\
\hline \multirow[t]{2}{*}{ Education * $\log (\mathrm{K} / \mathrm{L})$} & & $0.047^{* * *}$ & $0.045^{\star * *}$ & 0.038 & 0.005 & -0.003 & 0.018 \\
\hline & & {$[0.012]$} & {$[0.012]$} & {$[0.039]$} & {$[0.033]$} & {$[0.035]$} & {$[0.036]$} \\
\hline \multirow[t]{2}{*}{ Education * $\log (\mathrm{H} / \mathrm{L})$} & & $-0.167^{\star *}$ & $-0.163^{\star *}$ & $-0.165^{\star *}$ & $-0.148^{\star *}$ & -0.099 & $-0.129^{*}$ \\
\hline & & {$[0.073]$} & {$[0.073]$} & {$[0.073]$} & {$[0.060]$} & {$[0.073]$} & {$[0.069]$} \\
\hline \multirow[t]{2}{*}{ Education * Log GDPpc } & & & & 0.005 & 0.019 & 0.025 & 0.011 \\
\hline & & & & [0.030] & {$[0.028]$} & [0.028] & {$[0.029]$} \\
\hline \multirow[t]{2}{*}{ Education * Log Pop } & & & & -0.003 & 0.004 & 0.001 & 0.002 \\
\hline & & & & [0.005] & {$[0.006]$} & {$[0.006]$} & {$[0.006]$} \\
\hline \multirow[t]{2}{*}{ Education * Gini } & & & & & -0.002 & -0.000 & -0.001 \\
\hline & & & & & {$[0.001]$} & {$[0.001]$} & {$[0.001]$} \\
\hline \multirow[t]{2}{*}{ Education * ELF Ethnic } & & & & & -0.013 & 0.016 & 0.013 \\
\hline & & & & & [0.038] & [0.039] & {$[0.036]$} \\
\hline \multirow[t]{2}{*}{ Education * Democracy } & & & & & 0.001 & 0.001 & 0.002 \\
\hline & & & & & {$[0.003]$} & {$[0.004]$} & {$[0.004]$} \\
\hline \multirow[t]{2}{*}{ Education * Socialist } & & & & & 0.013 & 0.034 & 0.029 \\
\hline & & & & & {$[0.040]$} & {$[0.037]$} & {$[0.039]$} \\
\hline \multirow[t]{2}{*}{ Education * Obedience } & & & & & $-0.123^{\star \star}$ & $-0.114^{\star \star \star}$ & $-0.111^{\star *}$ \\
\hline & & & & & [0.045] & [0.038] & {$[0.046]$} \\
\hline \multirow[t]{2}{*}{ Age } & $0.042^{\star \star \star}$ & $0.038^{\star \star \star}$ & 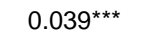 & $0.039^{\star \star \star}$ & $0.045^{\star \star \star}$ & $0.044^{\star \star \star}$ & $0.045^{\star \star \star}$ \\
\hline & [0.004] & [0.005] & [0.005] & [0.005] & [0.005] & [0.005] & [0.005] \\
\hline \multirow[t]{2}{*}{ Age squared } & $-0.00035^{\star \star \star}$ & $-0.00031^{\star \star \star}$ & $-0.00033^{\star \star \star}$ & $-0.00033^{\star \star \star}$ & $-0.00039^{\star \star \star}$ & $-0.00037^{\star \star \star}$ & $-0.00038^{\star \star \star}$ \\
\hline & {$[0.00004]$} & {$[0.00005]$} & {$[0.00005]$} & {$[0.00005]$} & {$[0.00005]$} & {$[0.00005]$} & {$[0.00005]$} \\
\hline \multirow[t]{2}{*}{ Female? (1=Yes; 0=No) } & $-0.450^{\star \star \star}$ & $-0.414^{\star \star \star}$ & $-0.414^{\star \star \star}$ & $-0.415^{\star \star \star}$ & $-0.380^{\star \star \star}$ & $-0.380^{* \star \star}$ & $-0.381^{\star \star \star}$ \\
\hline & [0.029] & {$[0.040]$} & {$[0.040]$} & {$[0.040]$} & {$[0.028]$} & {$[0.028]$} & {$[0.027]$} \\
\hline \multirow[t]{2}{*}{ Married? (1=Yes; 0=No) } & 0.017 & -0.008 & -0.007 & -0.007 & -0.000 & -0.000 & -0.005 \\
\hline & {$[0.017]$} & {$[0.021]$} & {$[0.021]$} & {$[0.021]$} & {$[0.022]$} & {$[0.022]$} & {$[0.018]$} \\
\hline \multirow[t]{2}{*}{ Number of children } & $-0.025^{\star \star \star}$ & $-0.022^{\star \star \star}$ & $-0.023^{\star \star \star}$ & $-0.023^{\star \star \star}$ & $-0.031^{\star \star \star}$ & $-0.030^{\star \star \star}$ & $-0.027^{\star \star \star}$ \\
\hline & {$[0.006]$} & {$[0.007]$} & {$[0.007]$} & [0.007] & [0.008] & {$[0.008]$} & {$[0.007]$} \\
\hline \multirow[t]{2}{*}{ Student? (1=Yes; 0=No) } & $0.246^{\star \star \star}$ & $0.245^{\star \star \star}$ & $0.228^{\star \star}$ & $0.227^{\star \star}$ & $0.315^{\star \star \star}$ & $0.309^{\star \star \star}$ & $0.304^{\star \star \star}$ \\
\hline & {$[0.056]$} & {$[0.084]$} & {$[0.085]$} & {$[0.086]$} & {$[0.050]$} & {$[0.049]$} & {$[0.043]$} \\
\hline \multirow[t]{2}{*}{ Employed? (1=Yes; 0=No) } & $0.110^{\star \star \star}$ & $0.112^{\star \star \star}$ & $0.109^{\star \star \star}$ & $0.109^{\star \star \star}$ & $0.078^{\star \star \star}$ & $0.076^{\star \star \star}$ & $0.079^{\star \star \star}$ \\
\hline & {$[0.016]$} & {$[0.020]$} & {$[0.020]$} & {$[0.020]$} & {$[0.023]$} & {$[0.025]$} & {$[0.021]$} \\
\hline \multirow[t]{2}{*}{ Income decile } & $0.037^{\star \star \star}$ & $0.038^{\star \star \star}$ & $0.037^{\star \star \star}$ & $0.037^{\star \star \star}$ & $0.043^{\star \star \star}$ & $0.033^{\star}$ & $0.044^{\star \star}$ \\
\hline & {$[0.006]$} & {$[0.009]$} & {$[0.009]$} & {$[0.009]$} & {$[0.010]$} & {$[0.019]$} & {$[0.020]$} \\
\hline Country-wave fixed effects? & Yes & Yes & Yes & Yes & Yes & Yes & Yes \\
\hline Excl. outlier countries? & No & No & Yes & Yes & Yes & Yes & Yes \\
\hline Income * Country-wave? & No & No & No & No & No & Yes & Yes \\
\hline Imputed Individual Controls? & No & No & No & No & No & No & Yes \\
\hline Observations & 114192 & 74822 & 72996 & 72996 & 53763 & 53763 & 64583 \\
\hline R-squared & 0.21 & 0.24 & 0.24 & 0.24 & 0.25 & 0.25 & 0.25 \\
\hline No. of countries & 72 & 47 & 45 & 45 & 36 & 36 & 36 \\
\hline No. of surveys & 105 & 66 & 64 & 64 & 49 & 49 & 49 \\
\hline
\end{tabular}

Notes: Standard errors are clustered by country, with *, **, and ${ }^{* \star *}$ denoting significance at the $10 \%, 5 \%$, and $1 \%$ levels respectively. All regressions include country-survey wave fixed effects. Columns (3)-(7) exclude countries with very extreme factor endowment ratios (differing from the sample mean by more than three standard deviations); this drops Singapore (with a low T/L ratio) and Uganda (with a low K/L ratio). Columns (6)-(7) control for income decile interacted with country-wave dummies. Column (7) imputes missing individual-level controls with their mean value by country-survey wave, while including a set of dummy variables to indicate whether each of these individual controls was originally missing (coefficients on these dummy variables not reported). 
Table 2

Education and Various WVS Measures of Political Participation (OLS)

\begin{tabular}{|c|c|c|c|c|c|c|c|c|c|c|}
\hline \multirow[t]{3}{*}{ Dependent variable: } & \multicolumn{2}{|c|}{ Interest in Politics } & \multicolumn{2}{|c|}{ Politics Important } & \multicolumn{2}{|c|}{ Discuss Politics } & \multicolumn{2}{|c|}{ Demonstrate } & \multicolumn{2}{|c|}{ Petition } \\
\hline & $(1)$ & (2) & (3) & (4) & $(5)$ & (6) & $(7)$ & (8) & (9) & (10) \\
\hline & OLS & OLS & OLS & OLS & OLS & OLS & OLS & OLS & OLS & OLS \\
\hline \multirow[t]{2}{*}{ Education } & $0.100^{\star * \star}$ & $0.243^{\star \star *}$ & $0.073^{\star \star *}$ & $0.202^{\star *}$ & $0.070^{\star \star \star}$ & 0.106 & $0.041^{\star \star}$ & $0.139^{* *}$ & $0.063^{\star \star *}$ & 0.023 \\
\hline & {$[0.015]$} & {$[0.079]$} & {$[0.014]$} & {$[0.097]$} & {$[0.015]$} & {$[0.072]$} & {$[0.018]$} & {$[0.066]$} & {$[0.019]$} & {$[0.085]$} \\
\hline \multirow[t]{2}{*}{ Education * $\log (T / L)$} & $0.010^{\star * *}$ & $0.015^{\star \star *}$ & $0.008^{* \star *}$ & $0.009^{*}$ & $0.006^{*}$ & $0.009^{* *}$ & $0.009^{* \star *}$ & $0.013^{\star *}$ & 0.007 & 0.005 \\
\hline & {$[0.002]$} & {$[0.005]$} & {$[0.003]$} & {$[0.005]$} & {$[0.003]$} & {$[0.004]$} & {$[0.003]$} & {$[0.005]$} & {$[0.004]$} & {$[0.007]$} \\
\hline \multirow[t]{2}{*}{ Education * $\log (K / L)$} & $0.021 * * *$ & 0.006 & $0.021^{* * *}$ & 0.024 & 0.008 & 0.002 & $0.024^{* * *}$ & $0.029 * *$ & 0.009 & -0.015 \\
\hline & {$[0.006]$} & {$[0.021]$} & [0.005] & {$[0.021]$} & {$[0.005]$} & {$[0.013]$} & {$[0.005]$} & {$[0.012]$} & {$[0.008]$} & {$[0.017]$} \\
\hline \multirow[t]{2}{*}{ Education * $\log (\mathrm{H} / \mathrm{L})$} & $-0.086^{\star *}$ & $-0.077^{\star}$ & $-0.090^{\star * *}$ & $-0.099^{* * *}$ & -0.032 & -0.032 & $-0.064^{\star *}$ & -0.025 & -0.03 & -0.019 \\
\hline & {$[0.033]$} & {$[0.041]$} & [0.029] & {$[0.032]$} & {$[0.028]$} & {$[0.025]$} & {$[0.028]$} & {$[0.022]$} & {$[0.038]$} & {$[0.032]$} \\
\hline \multirow[t]{2}{*}{ Education * Log GDPpc } & & 0.007 & & 0.004 & & 0.005 & & $-0.021 *$ & & 0.011 \\
\hline & & {$[0.016]$} & & {$[0.017]$} & & {$[0.011]$} & & {$[0.011]$} & & {$[0.014]$} \\
\hline \multirow[t]{2}{*}{ Education * Log Pop } & & -0.001 & & $-0.006^{\star}$ & & 0.001 & & $0.006^{\star *}$ & & 0.003 \\
\hline & & {$[0.004]$} & & {$[0.003]$} & & [0.002] & & {$[0.002]$} & & [0.003] \\
\hline \multirow[t]{2}{*}{ Education * Gini } & & $-0.001^{*}$ & & -0.000 & & -0.000 & & -0.000 & & 0.000 \\
\hline & & {$[0.000]$} & & {$[0.001]$} & & {$[0.000]$} & & {$[0.000]$} & & {$[0.000]$} \\
\hline \multirow[t]{2}{*}{ Education * ELF Ethnic } & & 0.008 & & 0.026 & & 0.01 & & -0.014 & & 0.009 \\
\hline & & {$[0.018]$} & & {$[0.021]$} & & {$[0.012]$} & & {$[0.016]$} & & {$[0.024]$} \\
\hline \multirow{2}{*}{ Education * Democracy } & & -0.000 & & -0.001 & & -0.002 & & $0.004^{\star \star \star}$ & & $0.004^{* *}$ \\
\hline & & {$[0.002]$} & & {$[0.002]$} & & {$[0.001]$} & & {$[0.001]$} & & {$[0.002]$} \\
\hline \multirow[t]{2}{*}{ Education * Socialist } & & 0.009 & & $0.029^{*}$ & & 0.019 & & $-0.032^{\star \star}$ & & 0.026 \\
\hline & & {$[0.026]$} & & {$[0.016]$} & & {$[0.012]$} & & {$[0.012]$} & & {$[0.016]$} \\
\hline \multirow[t]{2}{*}{ Education * Obedience } & & $-0.056^{\star *}$ & & -0.033 & & -0.027 & & $-0.033^{\star \star}$ & & $-0.044^{\star *}$ \\
\hline & & {$[0.025]$} & & {$[0.021]$} & & {$[0.017]$} & & {$[0.013]$} & & {$[0.017]$} \\
\hline \multirow{4}{*}{$\begin{array}{l}\text { Country-wave fixed effects? } \\
\text { Excl. outlier countries? } \\
\text { Income * Country-wave? } \\
\text { Imputed Individual Controls? }\end{array}$} & Yes & Yes & Yes & Yes & Yes & Yes & Yes & Yes & Yes & Yes \\
\hline & No & Yes & No & Yes & No & Yes & No & Yes & No & Yes \\
\hline & No & Yes & No & Yes & No & Yes & No & Yes & No & Yes \\
\hline & No & Yes & No & Yes & No & Yes & No & Yes & No & Yes \\
\hline Observations & 86829 & 71897 & 92856 & 77122 & 94045 & 77518 & 83263 & 72071 & 84085 & 72540 \\
\hline R-squared & 0.16 & 0.18 & 0.10 & 0.11 & 0.13 & 0.14 & 0.19 & 0.20 & 0.30 & 0.32 \\
\hline No. of countries & 50 & 37 & 52 & 38 & 52 & 38 & 49 & 37 & 49 & 37 \\
\hline No. of surveys & 69 & 50 & 75 & 54 & 76 & 54 & 70 & 52 & 71 & 52 \\
\hline
\end{tabular}

Notes: Standard errors are clustered by country, with *, **, and *** denoting significance at the $10 \%$, 5\%, and 1\% levels respectively. All regressions include: (i) individual-level controls for age, age squared, a gender dummy, a married dummy, number of children, a student dummy, an employment status dummy, and income decile; and (ii) country-survey wave fixed effects. For each dependent variable, the first column is a lean specification containing the interaction terms involving individual education and country factor endowments; the second column is a full specification that excludes country outliers (SGP, UGA), includes the income by country-wave dummy controls, imputes missing individual controls, and includes a set of dummy variables to indicate whether an individual control variable was imputed. 
Table 3

Education and Various WVS Measures of Political Participation (Ordered Logit)

\begin{tabular}{|c|c|c|c|c|c|c|c|c|c|c|}
\hline \multirow[t]{3}{*}{ Dependent variable: } & \multicolumn{2}{|c|}{ Interest in Politics } & \multicolumn{2}{|c|}{ Politics Important } & \multicolumn{2}{|c|}{ Discuss Politics } & \multicolumn{2}{|c|}{ Demonstrate } & \multicolumn{2}{|c|}{ Petition } \\
\hline & (1) & (2) & (3) & (4) & (5) & (6) & (7) & (8) & (9) & (10) \\
\hline & Ord. Logit & Ord. Logit & Ord. Logit & Ord. Logit & Ord. Logit & Ord. Logit & Ord. Logit & Ord. Logit & Ord. Logit & Ord. Logit \\
\hline \multirow[t]{2}{*}{ Education } & $0.218^{\star \star \star}$ & $0.490^{\star * \star}$ & $0.163^{\star \star *}$ & $0.415^{\star \star}$ & $0.233^{\star \star \star}$ & 0.293 & $0.151^{\star * *}$ & $0.425^{\star *}$ & $0.114^{\star \star \star}$ & 0.241 \\
\hline & [0.033] & [0.174] & [0.029] & [0.195] & {$[0.050]$} & {$[0.226]$} & [0.054] & [0.192] & {$[0.041]$} & {$[0.208]$} \\
\hline \multirow[t]{2}{*}{ Education * $\log (T / L)$} & $0.020^{\star * *}$ & $0.031^{\star \star *}$ & $0.017^{\star \star *}$ & $0.020^{\star *}$ & $0.020^{*}$ & $0.027^{\star *}$ & $0.019^{*}$ & $0.030^{* *}$ & $0.028^{\star *}$ & 0.027 \\
\hline & [0.004] & {$[0.010]$} & {$[0.005]$} & {$[0.010]$} & {$[0.011]$} & {$[0.011]$} & {$[0.010]$} & {$[0.015]$} & [0.012] & {$[0.018]$} \\
\hline \multirow[t]{2}{*}{ Education * $\log (\mathrm{K} / \mathrm{L})$} & $0.044^{\star \star *}$ & 0.02 & $0.041^{\star * *}$ & 0.046 & 0.025 & -0.003 & $0.062^{* * *}$ & 0.051 & 0.029 & -0.012 \\
\hline & {$[0.012]$} & {$[0.046]$} & {$[0.011]$} & {$[0.046]$} & {$[0.017]$} & {$[0.043]$} & {$[0.014]$} & {$[0.040]$} & {$[0.020]$} & {$[0.038]$} \\
\hline \multirow[t]{2}{*}{ Education * $\log (\mathrm{H} / \mathrm{L})$} & $-0.193^{\star \star \star}$ & $-0.202^{\star *}$ & $-0.198^{\star \star \star}$ & $-0.246^{* * *}$ & -0.117 & -0.124 & $-0.202^{\star *}$ & -0.033 & 0.002 & 0.095 \\
\hline & {$[0.074]$} & {$[0.081]$} & {$[0.060]$} & {$[0.068]$} & [0.092] & {$[0.084]$} & {$[0.084]$} & {$[0.072]$} & {$[0.090]$} & {$[0.070]$} \\
\hline \multirow[t]{2}{*}{ Education * Log GDPpc } & & 0.015 & & 0.013 & & 0.027 & & -0.049 & & -0.010 \\
\hline & & {$[0.035]$} & & {$[0.037]$} & & [0.033] & & {$[0.032]$} & & {$[0.034]$} \\
\hline \multirow[t]{2}{*}{ Education * Log Pop } & & -0.002 & & $-0.013^{*}$ & & 0.003 & & $0.013^{*}$ & & 0.009 \\
\hline & & {$[0.007]$} & & {$[0.007]$} & & {$[0.007]$} & & {$[0.007]$} & & {$[0.007]$} \\
\hline \multirow{2}{*}{ Education * Gini } & & -0.001 & & 0.000 & & -0.000 & & -0.001 & & -0.000 \\
\hline & & {$[0.001]$} & & {$[0.001]$} & & {$[0.001]$} & & {$[0.001]$} & & {$[0.001]$} \\
\hline \multirow[t]{2}{*}{ Education * ELF Ethnic } & & 0.025 & & 0.063 & & 0.037 & & -0.040 & & 0.044 \\
\hline & & {$[0.036]$} & & {$[0.045]$} & & {$[0.042]$} & & {$[0.054]$} & & {$[0.057]$} \\
\hline \multirow[t]{2}{*}{ Education * Democracy } & & 0.001 & & -0.001 & & -0.006 & & $0.010^{\star *}$ & & $0.012^{\star \star *}$ \\
\hline & & {$[0.004]$} & & [0.004] & & [0.004] & & [0.005] & & {$[0.004]$} \\
\hline \multirow[t]{2}{*}{ Education * Socialist } & & 0.034 & & $0.079 * *$ & & $0.074^{\star \star}$ & & $-0.082^{*}$ & & -0.017 \\
\hline & & {$[0.051]$} & & [0.032] & & {$[0.037]$} & & {$[0.043]$} & & [0.048] \\
\hline \multirow[t]{2}{*}{ Education * Obedience } & & $-0.113^{\star *}$ & & -0.064 & & -0.089 & & $-0.094^{*}$ & & $-0.119^{\star \star \star}$ \\
\hline & & {$[0.053]$} & & {$[0.046]$} & & {$[0.058]$} & & {$[0.048]$} & & {$[0.043]$} \\
\hline \multirow{4}{*}{$\begin{array}{l}\text { Country-wave fixed effects? } \\
\text { Excl. outlier countries? } \\
\text { Income * Country-wave? } \\
\text { Imputed Individual Controls? }\end{array}$} & Yes & Yes & Yes & Yes & Yes & Yes & Yes & Yes & Yes & Yes \\
\hline & No & Yes & No & Yes & No & Yes & No & Yes & No & Yes \\
\hline & No & Yes & No & Yes & No & Yes & No & Yes & No & Yes \\
\hline & No & Yes & No & Yes & No & Yes & No & Yes & No & Yes \\
\hline Observations & 86829 & 71897 & 92856 & 77122 & 94045 & 77518 & 83263 & 72071 & 84085 & 72540 \\
\hline R-squared & 0.07 & 0.08 & 0.04 & 0.04 & 0.07 & 0.08 & 0.11 & 0.11 & 0.17 & 0.18 \\
\hline No. of countries & 50 & 37 & 52 & 38 & 52 & 38 & 49 & 37 & 49 & 37 \\
\hline No. of surveys & 69 & 50 & 75 & 54 & 76 & 54 & 70 & 52 & 71 & 52 \\
\hline
\end{tabular}

Notes: Standard errors are clustered by country, with *, **, and *** denoting significance at the $10 \%$, 5\%, and 1\% levels respectively. All regressions include: (i) individual-level controls for age, age squared, a gender dummy, a married dummy, number of children, a student dummy, an employment status dummy, and income decile; and (ii) country-survey wave fixed effects. For each dependent variable, the first column is a lean specification containing the interaction terms involving individual education and country factor endowments; the second column is a full specification that excludes country outliers (SGP, UGA), includes the income by country-wave dummy controls, imputes missing individual controls, and includes a set of dummy variables to indicate whether an individual control variable was imputed. 
Table 4

Education and Voting in the CSES

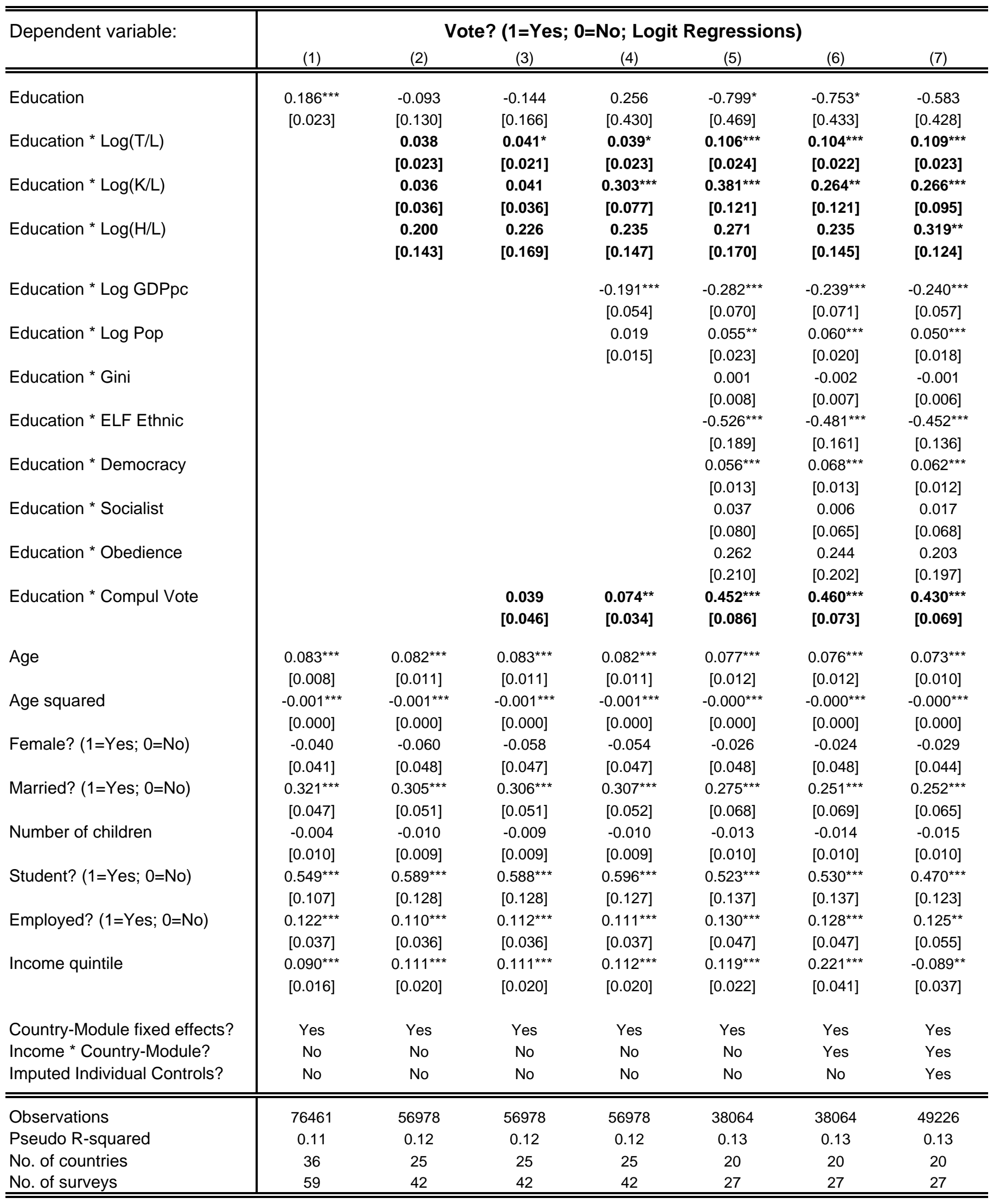

Notes: Standard errors are clustered by country, with *, **, and *** denoting significance at the 10\%, 5\%, and $1 \%$ levels respectively. All regressions include country-module fixed effects. Columns (6)-(7) control for income decile interacted with country-module dummies. Column (7) replaces missing individual-level controls with their mean value by country-module wave, while including a set of dummy variables to indicate whether each of these individual controls was originally missing (coefficients on these dummy variables not reported). There were no clear country outliers with very extreme factor endowment ratios (differing from the sample mean by more than three standard deviations). 
Table 5

The Cross-country Relationship between Increases in Schooling and Initial Country Factor Endowments

Dependent variable: Years of Schooling in 2000 - Years of Schooling in 1975

\begin{tabular}{|c|c|c|c|c|c|c|c|c|c|}
\hline Schooling variable (in years): & $\begin{array}{c}(1) \\
\text { Total } \\
\end{array}$ & $\begin{array}{c}(2) \\
\text { Total } \\
\end{array}$ & $\begin{array}{c}(3) \\
\text { Total } \\
\end{array}$ & $\begin{array}{c}(4) \\
\text { Total } \\
\end{array}$ & $\begin{array}{c}(5) \\
\text { Total } \\
\end{array}$ & $\begin{array}{c}(6) \\
\text { Total } \\
\end{array}$ & $\begin{array}{c}(7) \\
\text { Primary } \\
\end{array}$ & $\begin{array}{c}(8) \\
\text { Secondary } \\
\end{array}$ & $\begin{array}{c}(9) \\
\text { Higher }\end{array}$ \\
\hline Years of schooling, 1975 & $\begin{array}{l}-0.007 \\
{[0.047]}\end{array}$ & $\begin{array}{l}-0.011 \\
{[0.048]}\end{array}$ & $\begin{array}{l}-0.024 \\
{[0.047]}\end{array}$ & $\begin{array}{c}-0.218 * * \star \\
{[0.066]}\end{array}$ & $\begin{array}{c}-0.201^{\star \star *} \\
{[0.065]}\end{array}$ & $\begin{array}{c}-0.243^{* * *} \\
{[0.058]}\end{array}$ & $\begin{array}{c}-0.231^{\star \star *} \\
{[0.049]}\end{array}$ & $\begin{array}{l}-0.213 \\
{[0.135]}\end{array}$ & $\begin{array}{l}0.363^{\star *} \\
{[0.180]}\end{array}$ \\
\hline Democracy, 1975 & $\begin{array}{c}0.006 \\
{[0.028]}\end{array}$ & $\begin{array}{c}0.009 \\
{[0.029]}\end{array}$ & $\begin{array}{c}0.044 \\
{[0.034]}\end{array}$ & $\begin{array}{l}-0.013 \\
{[0.027]}\end{array}$ & $\begin{array}{l}0.107^{\star *} \\
{[0.041]}\end{array}$ & $\begin{array}{c}0.126 * \star \star \\
{[0.044]}\end{array}$ & $\begin{array}{l}0.080 * * \\
{[0.034]}\end{array}$ & $\begin{array}{l}0.041^{*} \\
{[0.023]}\end{array}$ & $\begin{array}{c}0.004 \\
{[0.006]}\end{array}$ \\
\hline $\log (T / L), 1975$ & & $\begin{array}{c}-0.118 \\
{[0.088]}\end{array}$ & $\begin{array}{c}-0.215^{\star \star} \\
{[0.099]}\end{array}$ & $\begin{array}{c}-0.065 \\
{[0.084]}\end{array}$ & $\begin{array}{l}-0.158 \\
{[0.097]}\end{array}$ & $\begin{array}{c}-0.548 * \star \\
{[0.232]}\end{array}$ & $\begin{array}{c}-0.127 \\
{[0.110]}\end{array}$ & $\begin{array}{c}-0.315^{\star *} \\
{[0.133]}\end{array}$ & $\begin{array}{c}-0.057^{\star \star} \\
{[0.027]}\end{array}$ \\
\hline Democracy * Log (T/L) & & & $\begin{array}{l}0.034^{*} \\
{[0.019]}\end{array}$ & & $\begin{array}{l}0.037^{* *} \\
{[0.015]}\end{array}$ & $\begin{array}{l}0.074^{\star *} \\
{[0.028]}\end{array}$ & $\begin{array}{l}0.023^{*} \\
{[0.013]}\end{array}$ & $\begin{array}{l}0.030 \star \\
{[0.017]}\end{array}$ & $\begin{array}{l}0.008 * \\
{[0.005]}\end{array}$ \\
\hline $\log (\mathrm{K} / \mathrm{L}), 1975$ & & & & $\begin{array}{c}0.496 * \star \star \\
{[0.089]}\end{array}$ & $\begin{array}{c}0.580 * \star * \\
{[0.085]}\end{array}$ & $\begin{array}{c}0.693^{\star \star \star} \\
{[0.104]}\end{array}$ & $\begin{array}{c}0.294^{* * *} \\
{[0.073]}\end{array}$ & $\begin{array}{c}0.307^{\star \star \star} \\
{[0.050]}\end{array}$ & $\begin{array}{c}0.059 * * \star \\
{[0.011]}\end{array}$ \\
\hline Democracy * $\log (\mathrm{K} / \mathrm{L})$ & & & & & $\begin{array}{c}-0.033^{\star \star} \\
{[0.015]}\end{array}$ & $\begin{array}{c}-0.035^{\star *} \\
{[0.014]}\end{array}$ & $\begin{array}{c}-0.035^{\star \star *} \\
{[0.010]}\end{array}$ & $\begin{array}{l}-0.005 \\
{[0.011]}\end{array}$ & $\begin{array}{l}-0.001 \\
{[0.002]}\end{array}$ \\
\hline Excl. outlier countries? & No & No & No & No & No & Yes & Yes & Yes & Yes \\
\hline $\begin{array}{l}\text { Observations } \\
\text { R-squared } \\
\text { No. of countries }\end{array}$ & $\begin{array}{c}96 \\
0.00 \\
96\end{array}$ & $\begin{array}{c}94 \\
0.03 \\
94\end{array}$ & $\begin{array}{c}94 \\
0.05 \\
94\end{array}$ & $\begin{array}{c}92 \\
0.24 \\
92\end{array}$ & $\begin{array}{c}92 \\
0.32 \\
92\end{array}$ & $\begin{array}{c}89 \\
0.35 \\
89\end{array}$ & $\begin{array}{c}89 \\
0.39 \\
89\end{array}$ & $\begin{array}{c}89 \\
0.38 \\
89\end{array}$ & $\begin{array}{c}87 \\
0.54 \\
87\end{array}$ \\
\hline
\end{tabular}

Notes: Robust standard errors are reported, with *, **, and *** denoting significance at the $10 \%, 5 \%$, and $1 \%$ levels respectively. The outliers dropped in Columns (6)-(9) are BHR, KWT and SGP which have an initial land-labor endowment more than three standard deviations smaller than the sample mean. 
Figure 1

Partial Scatterplots of the Coefficient of Individual Education against Country Characteristics

\section{A: Arable land per worker, $\log (T / L)$}

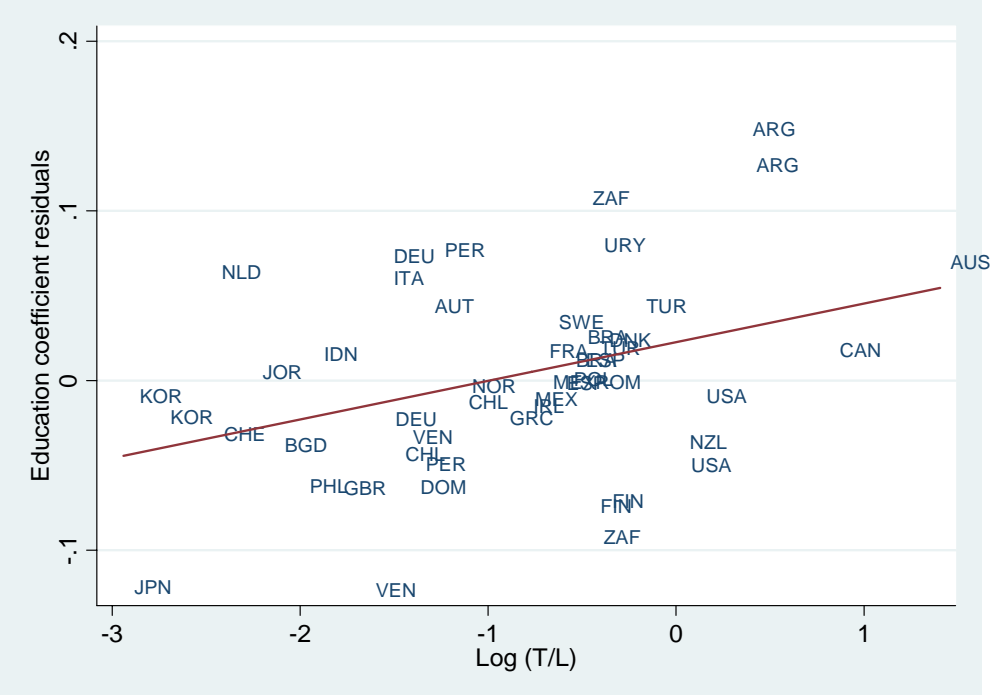

\section{B: Physical capital per worker, $\log (\mathrm{K} / \mathrm{L})$}

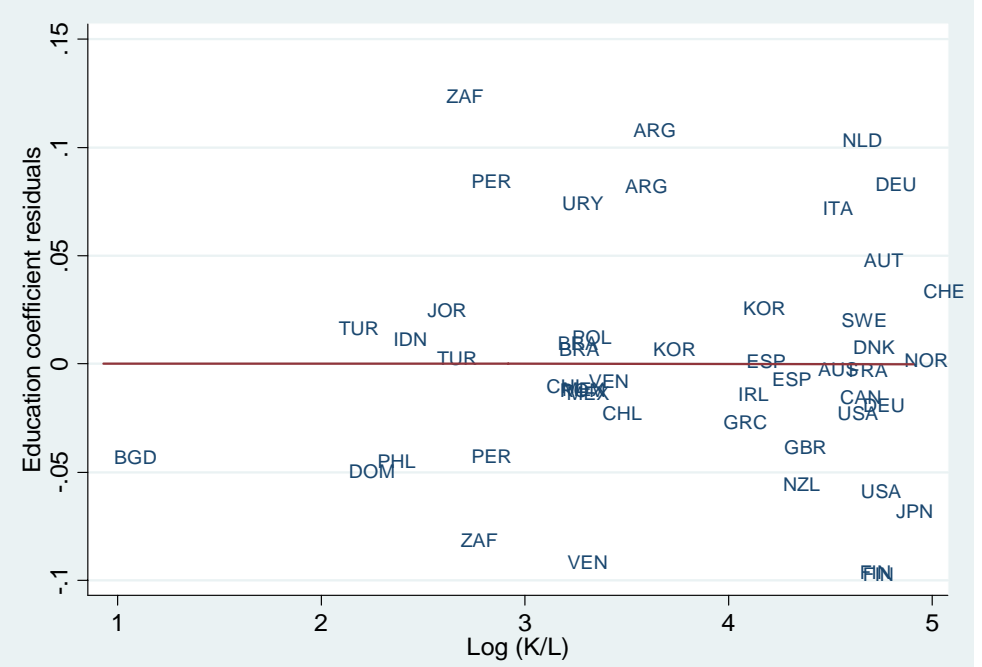

\section{C: Human capital per worker, $\log (\mathrm{H} / \mathrm{L})$}

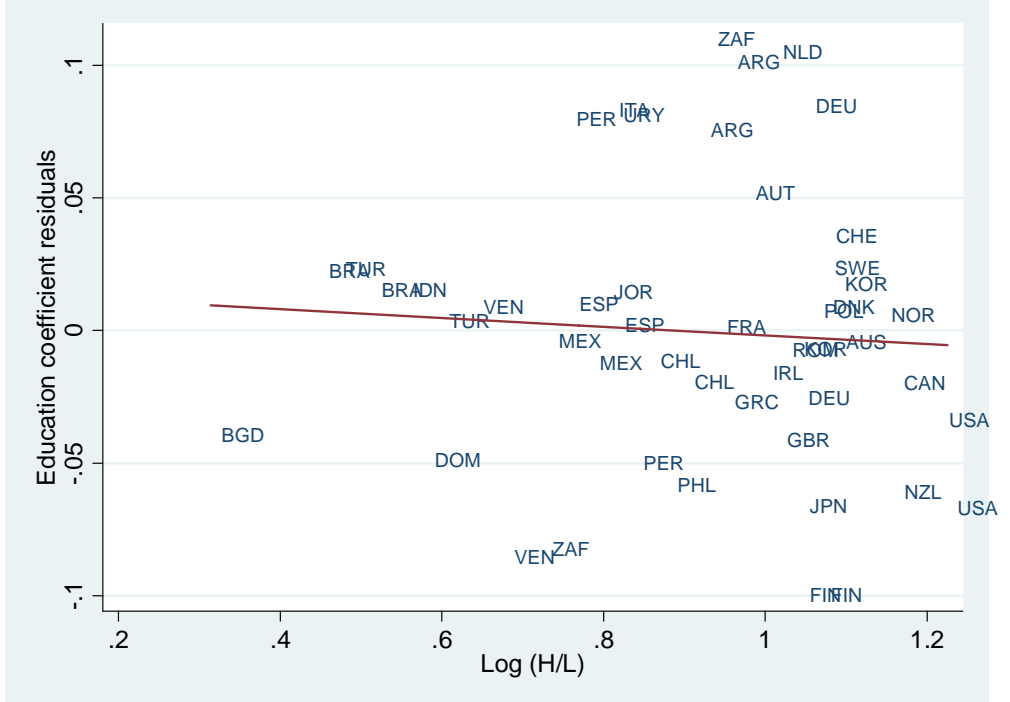

\section{D: Obedience}

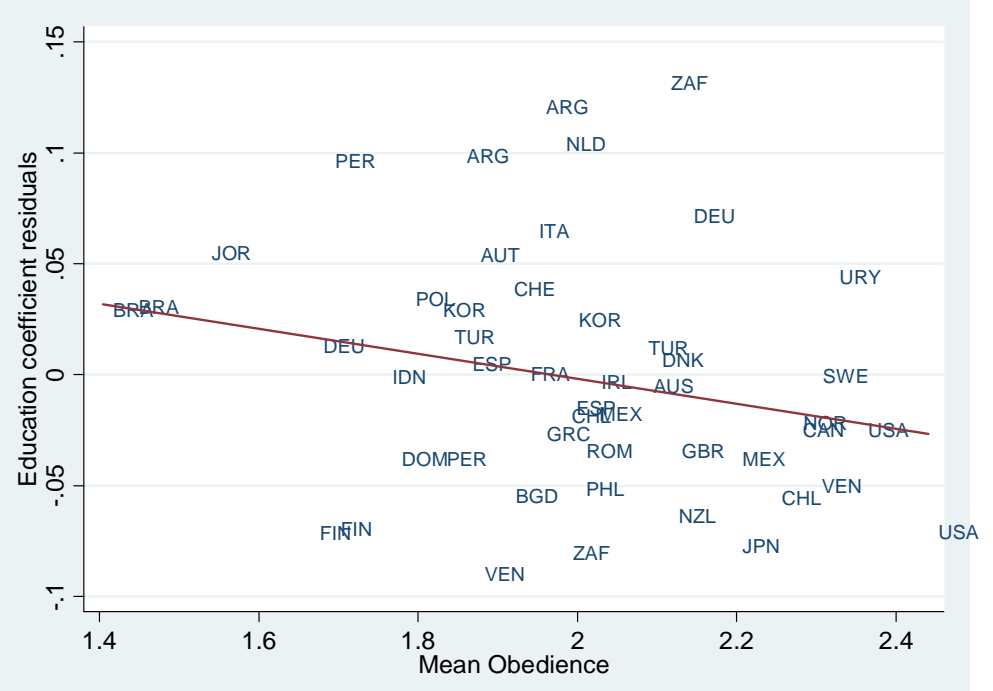

Notes: We use the first principal component measure of political participation from the WVS, and first regress this against individual education and a host of other respondent controls, including age, gender, and income decile, for each country-survey wave separately. (See Table 1 for the full list of individual controls, $\mathrm{V}_{\mathrm{i}}$.) We then collect the coefficients on education from the different country-waves and regress them against a set of country variables, to obtain these partial scatterplots for the education coefficients. (We use the full set of country variables, $\mathrm{W}_{\mathrm{ct}}$, from the Table 1, Column (5) specification.) 
Figure 2

Timeline of Events

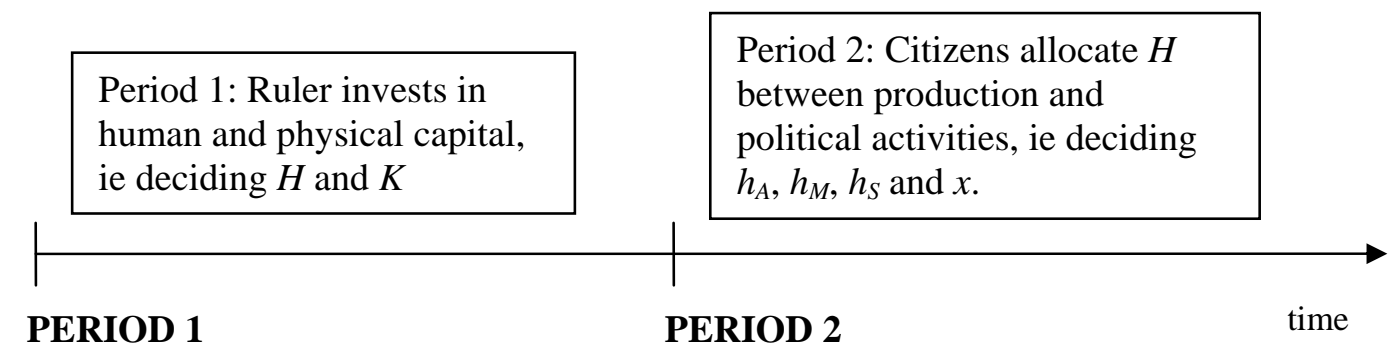




\section{Appendix Table 1 List of Countries in Sample}

\section{A: World Values Survey (47 Countries, 66 surveys)}

Argentina (ARG): Wave 3-4; Australia (AUS): Wave 3; Austria (AUT): Wave 4; Bangladesh (BGD): Wave 3-4; Brazil (BRA): Wave 2-3; Canada (CAN): Wave 4; Switzerland (CHE): Wave 2-3; Chile (CHL): Wave 3-4; Colombia (COL): Wave 3; Germany (DEU): Wave 3-4; Denmark (DNK): Wave 4; Dominican Rep (DOM): Wave 3; Algeria (DZA): Wave 4; Egypt (EGY): Wave 4; Spain (ESP): Wave 3-4; Finland (FIN): Wave 3-4; France (FRA): Wave 4; United Kingdom (GBR): Wave 4; Greece (GRC): Wave 4; Indonesia (IDN): Wave 4; India (IND): Wave 2-4; Ireland (IRL): Wave 4; Iceland (ISL): Wave 4; Italy (ITA): Wave 4; Jordan (JOR): Wave 4; Japan (JPN): Wave 4; Korea, Rep of (KOR): Wave 3-4; Mexico (MEX): Wave 3-4; Netherlands (NLD): Wave 4; Norway (NOR): Wave 3; New Zealand (NZL): Wave 3; Pakistan (PAK): Wave 4; Peru (PER): Wave 3-4; Philippines (PHL): Wave 4; Poland (POL): Wave 4; Puerto Rico (PRI): Wave 3; Romania (ROM): Wave 3; Singapore (SGP): Wave 4; El Salvador (SLV): Wave 3; Sweden (SWE): Wave 3; Turkey (TUR): Wave 2-4; Uganda (UGA): Wave 4; Uruguay (URY): Wave 3; United States (USA): Wave 3-4; Venezuela (VEN): Wave 3-4; South Africa (ZAF): Wave 2-4; Zimbabwe (ZWE): Wave 4

Notes: Tabulated for the regression sample in the specification in Table 1, Column (2), where the dependent variable is the first principal component of the five WVS political participation measures. Wave 2: 1989-1993; Wave 3: 1994-1999; Wave 4: 1999-2004.

\section{B: Comparative Study of Electoral Systems (25 Countries, 42 surveys)}

Brazil (BRA): Module 2; Canada (CAN): Module 1-2; Switzerland (CHE): Module 1-2; Germany (DEU): Module 1-2; Spain (ESP): Module 1-2; Finland (FIN): Module 2;

France (FRA): Module 2; United Kingdom (GBR): Module 1-2; Hungary (HUN): Module 1-2; Ireland (IRL): Module 2; Iceland (ISL): Module 1-2; Israel (ISR): Module 1-2; Japan (JPN): Module 2; Korea, Rep of (KOR): Module 2; Mexico (MEX): Module 1-2; Netherlands (NLD): Module 1-2; Norway (NOR): Module 1-2; New Zealand (NZL): Module 1-2; Peru (PER): Module 1; Philippines (PHL): Module 2; Poland (POL): Module 1-2; Portugal (PRT): Module 1-2; Romania (ROM): Module 1-2; Sweden (SWE): Module 1-2; United States (USA): Module 1-2

Notes: Tabulated for the regression sample in the specification in Table 4, Column (3), where the dependent variable is a binary variable for whether the respondent voted in the election in question. Module 1: 1996-2002; Module 2: 2001-2006. 
Appendix Table 2

Summary statistics: World Values Survey

\begin{tabular}{|c|c|c|c|c|c|}
\hline & 10th & Median & 90th & Mean & Std Dev \\
\hline \multicolumn{6}{|l|}{$\frac{\text { Measures of political participaton }}{\text { (country-survey wave means taken) }}$} \\
\hline Interest in Politics (Range: 0 to 3 ) & 0.88 & 1.33 & 1.73 & 1.33 & 0.31 \\
\hline Importance of Politics (Range: 0 to 3 ) & 0.94 & 1.31 & 1.63 & 1.30 & 0.25 \\
\hline Discuss Politics (Range: 0 to 2 ) & 0.65 & 0.83 & 1.04 & 0.83 & 0.16 \\
\hline Demonstration (Range: 0 to 2 ) & 0.28 & 0.71 & 1.04 & 0.70 & 0.26 \\
\hline Petition (Range: 0 to 2 ) & 0.58 & 0.98 & 1.59 & 1.08 & 0.40 \\
\hline $\begin{array}{l}\text { First Principal Component } \\
\text { Individual-level controls (WVS) } \\
\text { (country-survey wave means taken) }\end{array}$ & -0.84 & -0.03 & 0.70 & -0.05 & 0.56 \\
\hline Age & 35.1 & 39.5 & 46.6 & 40.3 & 4.9 \\
\hline Gender (0=Male; 1=Female) & 0.47 & 0.50 & 0.57 & 0.51 & 0.04 \\
\hline Marital Status (0=Not married; $1=$ Married) & 0.53 & 0.61 & 0.72 & 0.62 & 0.08 \\
\hline Number of children & 1.49 & 2.02 & 2.75 & 2.02 & 0.46 \\
\hline Student (0=Not Student; $1=$ Student) & 0.03 & 0.07 & 0.15 & 0.08 & 0.05 \\
\hline Employed (0=Unemployed; 1=Employed) & 0.45 & 0.55 & 0.67 & 0.56 & 0.09 \\
\hline Income decile (1=Lowest; 10=Highest) & 3.2 & 4.7 & 5.7 & 4.6 & 1.0 \\
\hline $\begin{array}{l}\text { Education (1=Lowest; 8=Highest) } \\
\text { Country-level variables }\end{array}$ & 3.5 & 4.3 & 5.7 & 4.5 & 0.8 \\
\hline $\log (T / L)$ & -2.51 & -1.08 & 0.02 & -1.24 & 1.28 \\
\hline $\log (K / L)$ & 1.66 & 3.22 & 4.61 & 3.27 & 1.25 \\
\hline $\log (\mathrm{H} / \mathrm{L})$ & 0.47 & 0.87 & 1.09 & 0.82 & 0.25 \\
\hline Log GDP per capita (constant 2000 US\$) & 6.24 & 8.55 & 10.21 & 8.51 & 1.43 \\
\hline Log Population & 14.78 & 16.85 & 18.34 & 16.70 & 1.49 \\
\hline Gini & 27.85 & 38.49 & 55.49 & 40.15 & 10.58 \\
\hline ELF Ethnic & 0.06 & 0.32 & 0.71 & 0.34 & 0.23 \\
\hline Democracy & 2 & 8.2 & 10 & 7.4 & 3.1 \\
\hline Socialist $(0=\mathrm{No} ; 1=\mathrm{Yes})$ & 0 & 0 & 0 & 0.03 & 0.17 \\
\hline Obedience ( $0=$ Lowest; $2=$ Highest) & 0.69 & 0.98 & 1.27 & 0.97 & 0.22 \\
\hline
\end{tabular}

Notes: Tabulated for the sample of 66 surveys in the regression specification in Table 1, Column (2), where the dependent variable is the first principal component of the five political participation measures. 
Appendix Table 3

Summary statistics: Comparative Study of Electoral Systems

\begin{tabular}{|c|c|c|c|c|c|}
\hline & 10th & Median & 90th & Mean & Std Dev \\
\hline \multicolumn{6}{|l|}{$\frac{\text { Measures of political participaton }}{\text { (country-survey module means taken) }}$} \\
\hline $\begin{array}{l}\text { Vote }(0=\text { Did not vote; } 1=\text { Voted) } \\
\frac{\text { Individual-level controls (CSES) }}{\text { (country-survey module means taken) }}\end{array}$ & 0.72 & 0.85 & 0.92 & 0.83 & 0.10 \\
\hline Age & 39.8 & 45.8 & 50.4 & 45.6 & 4.05 \\
\hline Gender (0=Male; $1=$ Female) & 0.49 & 0.52 & 0.57 & 0.52 & 0.03 \\
\hline Marital Status ( $0=$ Not married; $1=$ Married) & 0.57 & 0.64 & 0.70 & 0.64 & 0.06 \\
\hline Number of children & 0.53 & 0.75 & 1.62 & 0.92 & 0.49 \\
\hline Student (0=Not Student; $1=$ Student) & 0.02 & 0.05 & 0.09 & 0.05 & 0.03 \\
\hline Employed (0=Unemployed; $1=$ Employed) & 0.46 & 0.60 & 0.68 & 0.59 & 0.10 \\
\hline Income quintile (1=Lowest; 5=Highest) & 2.7 & 3.0 & 3.1 & 2.9 & 0.2 \\
\hline $\begin{array}{l}\text { Education (1=Lowest; } 8=\text { Highest) } \\
\text { Country-level variables }\end{array}$ & 4.1 & 5.0 & 5.9 & 5.0 & 0.7 \\
\hline $\log (T / L)$ & -2.47 & -0.86 & -0.19 & -1.22 & 1.04 \\
\hline $\log (K / L)$ & 3.11 & 4.35 & 4.83 & 4.14 & 0.69 \\
\hline $\log (H / L)$ & 0.80 & 1.03 & 1.18 & 1.01 & 0.16 \\
\hline Log GDP per capita (constant 2000 US\$) & 8.07 & 9.89 & 10.37 & 9.44 & 0.98 \\
\hline Log Population & 14.74 & 16.54 & 17.91 & 16.33 & 1.55 \\
\hline Gini & 27.71 & 31.98 & 49.30 & 34.76 & 8.36 \\
\hline ELF Ethnic & 0.06 & 0.16 & 0.54 & 0.26 & 0.21 \\
\hline Democracy & 7.4 & 10 & 10 & 9.1 & 1.8 \\
\hline Socialist $(0=\mathrm{No} ; 1=\mathrm{Yes})$ & 0 & 0 & 1 & 0.14 & 0.35 \\
\hline Obedience ( $0=$ Lowest; $2=$ Highest) & 0.74 & 1.03 & 1.28 & 1.04 & 0.19 \\
\hline Compulsory voting $(0=\mathrm{No} ; 1=\mathrm{Yes})$ & 0 & 0 & 1 & 0.14 & 0.35 \\
\hline
\end{tabular}

Notes: Tabulated for the sample of 42 surveys in the regression specification in Table 4, Column (3), where the dependent variable is the binary voting variable. 